\title{
Model-based analysis of photoinitiated coating degradation under artificial exposure conditions
}

\author{
Søren Kiil
}

(C) The Author(s) 2011. This article is published with open access at Springerlink.com

\begin{abstract}
Coating degradation mechanisms of thermoset coatings exposed to ultraviolet radiation and humidity at constant temperature are investigated. The essential processes, photoinitiated oxidation reactions, intrafilm oxygen permeability, water absorption and diffusion, reduction of crosslink density, and development of a thin surface oxidation zone are quantified and a mathematical model for degrading coatings developed. Front-tracking techniques are used to determine the rate of movement of the oxidation and ablation fronts, the positions of which define the extension of the surface oxidation zone. Three previous and independent experimental investigations with two-component, densely crosslinked, epoxy-amine model coatings were selected for verification of the mathematical model. Simulations can match and explain transient mass loss and coating thickness reduction data and are in agreement with infrared measurements of carbonyl groups formed in the surface zone. The thickness of the stable surface oxidation zone, which is established after an initial ablation lag time, is estimated by the model to $0.5-$ $2 \mu \mathrm{m}$ in good agreement with previous measurements. Simulated concentration profiles of active groups, oxygen, and radicals in the stable surface oxidation zone are presented and analyzed. The mathematical model can be used for obtaining a quantitative insight into the degradation of thermoset coatings and has potential, after further development, to complete commercial coatings and dynamic exposure conditions, to become a supplementing tool for predicting in-service coating behavior based on accelerated laboratory measurements.
\end{abstract}

S. Kiil $(\square)$

Department of Chemical and Biochemical Engineering,

Technical University of Denmark, Building 229, 2800

Kongens Lyngby, Denmark

e-mail: sk@kt.dtu.dk
Keywords Exterior durability, Materials, Weathering stress, Chain scission, Accelerated testing, Network degradation

\section{List of symbols}

\section{Variables}

$A$

$C_{i} \quad$ Concentration of component $i, \mathrm{~mol} / \mathrm{m}^{3}$

Coating area exposed to ultraviolet radiation, $\mathrm{m}^{2}$ coating

$C_{\mathrm{CCO}} \quad$ Initial concentration of "bridges" (CC) in network structure, $\mathrm{mol} / \mathrm{m}^{3}$ coating

$C_{\mathrm{CHOHO}}$ Initial concentration of $\mathrm{CHOH}$ groups in network structure, $\mathrm{mol} / \mathrm{m}^{3}$ coating

$C_{\mathrm{CH}_{2} \mathrm{NO}}$ Initial concentration of $\mathrm{CH}_{2} \mathrm{~N}$ groups in network structure, $\mathrm{mol} / \mathrm{m}^{3}$ coating

$C_{\mathrm{PhO}} \quad$ Initial concentration of phenoxy groups in network structure, $\mathrm{mol} / \mathrm{m}^{3}$ coating

$D_{i} \quad$ Intrafilm diffusion coefficient of component $i$ (water or oxygen), $\mathrm{m}^{2} / \mathrm{s}$

$D_{\mathrm{o}} \quad$ Preexponential factor for diffusion coefficient, $\mathrm{m}^{2} / \mathrm{s}$

E Activation energy (reaction or diffusion), $\mathrm{J} / \mathrm{mol}$

$E_{l} \quad$ Radiation intensity at position $l$ in coating, $\mathrm{W} / \mathrm{m}^{2}$

$E_{\mathrm{o}} \quad$ Radiation intensity at the coating surface, $\mathrm{W} / \mathrm{m}^{2}$

$E_{\mathrm{o}, \mathrm{S}} \quad$ Radiation intensity at the coating surface in region of spectral sensitivity, $\mathrm{W} / \mathrm{m}^{2}$ Functionality of reactant $i$

$h \quad$ Planck's constant or percentage of water in coating sample at equilibrium, $\mathrm{J} \mathrm{s}$

$i \quad$ Component $i$ 


\begin{tabular}{|c|c|}
\hline$k_{i}$ & $\begin{array}{l}\text { Rate constant of reaction } i,\left(\mathrm{~m}^{2} / \mathrm{W}\right)^{1 / 2} \mathrm{~s}^{-1} \text {, } \\
\left(\mathrm{m}^{3} / \mathrm{mol} \mathrm{s}\right) \text { or }\left(\mathrm{m}^{3} / \mathrm{mol}\right)^{5} \mathrm{~s}\end{array}$ \\
\hline$l$ & Position in coating, $\mathrm{m}$ \\
\hline$l_{\mathrm{A}}$ & Position of moving ablation front, $\mathrm{m}$ \\
\hline$l_{\mathrm{o}}$ & Initial coating thickness, $\mathrm{m}$ \\
\hline$l_{\mathrm{ox}}$ & Position of moving oxidation front, $\mathrm{m}$ \\
\hline$\Delta m$ & Mass loss from coating, $\mathrm{kg}$ \\
\hline$m_{\mathrm{o}}$ & Initial mass of coating, $\mathrm{kg}$ \\
\hline$M_{\mathrm{W}, i}$ & Molar mass of component $i, \mathrm{~kg} / \mathrm{mol}$ \\
\hline$n$ & $\begin{array}{l}\text { Number of repeating units in epoxy } \\
\text { backbone }\end{array}$ \\
\hline$P_{i}^{\text {air }}$ & Partial pressure of component $i$ in air, $\mathrm{Pa}$ \\
\hline$r$ & $\begin{array}{l}\text { Stoichiometric ratio between epoxy and } \\
\text { amine (active hydrogen) functional groups }\end{array}$ \\
\hline$\left(-r_{j, i}\right)$ & $\begin{array}{l}\text { Rate of reaction } j \text { with respect to } \\
\text { component } i, \mathrm{~mol} /\left(\mathrm{m}^{3} \text { solid coating } \mathrm{s}\right)\end{array}$ \\
\hline$R$ & Universal gas constant, $\mathrm{J} /(\mathrm{mol} \mathrm{K})$ \\
\hline$R \cdot$ & Radical \\
\hline ROO & Radical \\
\hline RH & Relative humidity in UV-chamber \\
\hline $\mathrm{RH}_{\mathrm{O}}$ & $\begin{array}{l}\text { Relative humidity in room where coatings } \\
\text { were stored prior to exposure }\end{array}$ \\
\hline$S_{\text {eq }}$ & $\begin{array}{l}\text { Equilibrium solubility of oxygen in } \\
\text { coating, } \mathrm{mol} /\left(\mathrm{m}^{3} \text { coating } \mathrm{Pa}\right)\end{array}$ \\
\hline$t$ & Time, $\mathrm{s}$ \\
\hline$T$ & Air temperature, $\mathrm{K}$ \\
\hline$T_{\mathrm{g}}$ & Glass transition temperature of coating, $\mathrm{K}$ \\
\hline$T_{\mathrm{o}}$ & Reference temperature, $\mathrm{K}$ \\
\hline$v$ & Frequency of light, $\mathrm{Hz}$ \\
\hline$v_{\mathrm{e}}^{\mathrm{o}}$ & Initial crosslink density, $\mathrm{mol} / \mathrm{m}^{3}$ coating \\
\hline$V$ & Local volume of coating $\left(=V_{\mathrm{o}}(1-\varepsilon)\right), \mathrm{m}^{3}$ \\
\hline$V_{\mathrm{o}}$ & $\begin{array}{l}\text { Local volume of coating at zero porosity, } \\
\mathrm{m}^{3}\end{array}$ \\
\hline$X_{\mathrm{CL}}$ & $\begin{array}{l}\text { Conversion of epoxy chains in the epoxy- } \\
\text { amine network (defined by equation 19) }\end{array}$ \\
\hline$X_{\mathrm{CL}, \max }$ & Value of $X_{\mathrm{CL}}$ at the moving ablation front \\
\hline$y_{i}$ & $\begin{array}{l}\text { Dimensionless concentration of } \\
\text { component } i\left(=C_{i} / C_{i \mathrm{O}}\right)\end{array}$ \\
\hline
\end{tabular}

\section{Greek letters}

$\begin{array}{ll}\alpha_{\mathrm{Ph}} & \text { Molar absorptivity of phenoxy group, } \mathrm{m}^{2} / \mathrm{mol} \\ \varepsilon & \text { Porosity } \\ \rho_{\mathrm{F}} & \text { Film (coating) density, } \mathrm{kg} / \mathrm{m}^{3} \\ \phi & \text { Quantum yield of binder (ratio of number of } \\ & \text { bonds broken per photon absorbed) }\end{array}$

\author{
Subscripts \\ CC "Bridge" in epoxy structure (see Fig. 1) \\ E Epoxy resin \\ $i \quad$ Component $i$
}
PA Polyamine crosslinker
W Water
$\mathrm{O}$ Initial value

\section{Superscript \\ o Reference value in sensitivity analysis}

\section{Introduction}

Exterior coatings exposed to solar ultraviolet (UV) radiation, heat, moisture, and other environmental stresses degrade through a number of processes collectively referred to as weathering. ${ }^{1}$ For modern high-performance coatings, weathering is usually a slow process often taking 5 years or longer before a critical performance property can be said to have failed. ${ }^{2}$ In the case of an automotive clear coating, the lifetime expectancy is typically 10 years, whereas for a topcoat of an industrial anticorrosive coating system, the specified service lifetime can be more than 20 years. ${ }^{3}$ Coating failure can be aesthetic (e.g., gloss loss or discoloration) or protective (e.g., thickness reduction or loss of mechanical properties). Due to new products being continuously developed by the coatings industry, there is a great need for accelerated weathering tests as evidenced by the abundant literature available on the topic (overviews are provided, e.g., in the recent books by Schulz ${ }^{1}$ and Wypych $^{4}$ ). Accelerated testing can be done in laboratory exposure equipment, using high radiation intensity and/or high temperature and relative humidity, or outdoor in climatically stable regions, such as the very sunny reference climates in Miami, Florida, where the relative humidity is high, and Phoenix, Arizona, where the air is very dry. ${ }^{1}$ However, it is essential that the exposure strategies developed allow valid extrapolations to in-service exposure conditions. ${ }^{1,5,6}$ Efforts in this direction have been ongoing for at least 100 years ${ }^{7}$ with the first UV-chamber being introduced by Atlas in 1918. ${ }^{8}$ To analyze and improve the correlations between laboratory and field data and increase the understanding of coating behavior during accelerated exposure conditions it is of relevance to quantify the underlying physical and chemical mechanisms and develop overall modeling tools. ${ }^{9-11}$ Mathematical models can also help to map the coupling of individual rate phenomena.

\section{Quantification of rate phenomena and mathematical model}

In this work a mathematical model which quantifies degradation of simple thermoset model coatings exposed to UV radiation and humidity, at room to slightly elevated temperatures, is developed. To capture 
numerically the very thin surface oxidation zone that develops upon exposure, front-tracking strategies are used to calculate the rate of movement of the oxidation and ablation fronts, the positions of which define the width of the oxidation zone. Simulations with the model for epoxy-amine coatings are compared with three experimental data series obtained by Nguyen et al., ${ }^{12}$ Rezig et al., ${ }^{13}$ and Guillot et al. ${ }^{14}$ (the latter with data also available in Monney et al. ${ }^{15}$ ), which include transient mass loss and thickness reduction data as well as infrared measurements of carbonyl groups in the oxidation zone. These experimental data, supplemented by other investigations, allow a thorough verification of the model and many of the underlying assumptions (a similar approach was used to model simultaneous solvent evaporation and chemical curing in thermoset coatings ${ }^{16}$ ). The significance of various degradation phenomena are subsequently analyzed using the model. It should be mentioned that the model is relevant for industrial protective coatings and therefore does not include a direct description of how the gloss develops, but rather focuses on prediction of mass loss and ablation rates (thickness reduction).

\section{Previous mathematical models of coating degradation}

When working with exterior durability of coatings, an essential activity is to develop mathematical models of the coating behavior, which can be verified or "calibrated" using data obtained in accelerated laboratory experiments and then subsequently use these models for making extrapolations to in-service conditions. This is a difficult task, but essential for both end-use customers and the coatings industry. There are several earlier attempts to model degradation of coatings exposed to weathering. The mathematical models can be based on either a stochastic (statistical) approach, so-called reliability theory, leading to cumulative damage models, or quantitative mechanistic models, based on knowledge of the underlying degradation mechanisms. ${ }^{10,17}$ Another distinction can be made between the various predictions that the models undertake or the definition of service life used. For exterior house paints or automobile coatings, gloss loss is often of great importance, whereas for industrial protective coatings, loss of mechanical properties (expressed, e.g., by mass loss or thickness reduction), are typically of more concern. In the coatings field, the models based on reliability theory appear to start with the work of Martin, ${ }^{18}$ who developed a stochastic model for degradation of poly(methyl methacrylate) films. Martin's model uses a Poisson distribution for computing the probability of chain scissions as a function of temperature and radiation intensity and another probability factor estimates if a performance parameter will be greater than a minimum specified value after a given number of chain scissions. Service life is defined as the time after which an unacceptable portion of a nominal population of films have failed. The model was validated against 25 data sets. Later stochastic models are described in, e.g., Martin.,19 Calibration of the models, to estimate dosage and damage functions, require extensive laboratory exposure data sets where the three main weathering factors-temperature, relative humidity, and spectral UV radiation - are varied in both space and time. ${ }^{7}$ A demonstration of an impressive device that can undertake such an experimental exercise in a fast and controlled manner, an integrating sphere-based UV exposure chamber, was reported by the National Institute of Standards and Technology, NIST. ${ }^{8}$ Subsequent to calibration, the cumulative damage models are used to predict the performance of the coatings during natural exposure (the general methodology is provided in detail in Martin et al. ${ }^{20}$ and two specific examples, on selected coatings, are available in Guseva et al. ${ }^{21}$ and Dickens ${ }^{22}$ ). Hinderliter and Croll ${ }^{23}$ have used a statistical Monte Carlo approach to simulate coating degradation, in their work defined as surface erosion. Using repeated calculations of random events taking place at the coating surface, a correlation can be established between coating degradation (e.g., gloss loss) and any number of input variables (e.g., pigment volume concentration). This method has potential for improving the understanding of how gloss loss develops.

The mechanistic models are based on mathematical descriptions of the physical and chemical phenomena taking place in coatings during exposure. Any level of complexity can, in principle, be obtained, but if the model contains too many unknown parameters it is not practical to use. On the contrary, if the physics and chemistry are too simple, the predictive value will not be high. The mechanistic models also require calibration to estimate model parameters, but as a starting point, the data required will be less than that for the stochastic models, though the more data available the better. Mechanistic models can be used to suggest improvements in accelerated test procedures by identifying the key events in coating degradation ${ }^{9}$ and evaluating accelerated coating exposure scenarios. However, not many mechanistic models are available. Bauer $^{17}$ appears to have initiated a quantitative formalism, using in his work so-called "time-to-failure models" which should be based on fundamental studies of the chemistry and physics of failure. Distribution functions are recommended to describe the statistical variation of the key material and exposure parameters. In Bauer's work, the approach suggested is illustrated on two different hypothetical mechanisms, but not tried out and validated on a practical coating case. Wood and Robien ${ }^{24}$ have set up a model of weathering-induced mass and gloss loss in thermoplastic coatings simulating the constant mass loss period as a function of pigment volume concentration. The degradation chemistry employed is not discussed and appears to be indirectly considered through one or more calibration parameters. Wood and Robien find 
that the constant mass loss rate predicted is $3-4$ times higher than the measured value and offer a number of explanations for this observation. Apart from these studies, no other mechanistic models have been identified.

Summarizing the above analysis of previous investigations, the following conclusions are reached: for optimization of a given coating, the present statistical models based on reliability theory, though requiring many systematic laboratory experiments, seem to be the most direct way to proceed. In terms of understanding and analysis, mechanisms of photoinitiated coating degradation have not been quantified to an extent that allows a detailed analysis of accelerated exposure protocols and data. Very few models have been developed and several important rate phenomena are not included in the existing models. In addition, validation of the existing models against a sufficiently large set of experimental data is lacking.

\section{Outline of relevant epoxy-amine degradation mechanism}

Most of the earlier degradation studies have focused on acrylic-melamine coatings for automobiles. More recent studies have used epoxy-amine networks with or without pigments as reference systems because of their abundant use as protective coatings, insulators in electronics, and as structural composites often exposed to direct sunlight. Though a focus on other systems has been encouraged, ${ }^{25}$ epoxy-amine systems are presently the most relevant systems to use for validation of quantitative models because of the large amount of data available in the literature for those systems. In Fig. 1 the structures of the epoxy binder and epoxyamine network, relevant for this work, are shown.

\section{Mechanism of photoinitiated oxidative degradation of epoxy-amine networks}

Photooxidation of epoxy networks, whether crosslinked with amine or other curing agents, is complicated. Monney et al. ${ }^{26}$ have trapped and measured volatile photoproducts and the degradation pathways are many, each one consisting of many elementary steps. In terms of a mathematical model, this calls for a simplified closed-loop mechanism as demonstrated by Colin et al. ${ }^{27}$ for a thermal oxidation problem. Such a reduction is necessary to avoid a prohibitive complexity of the overall mathematical model and can be justified if all relevant experimental observations can be described by the model. Based on the detailed studies of Bellenger, Verdu, and co-workers ${ }^{28-33}$ the following reduced mechanism can be proposed

$$
\begin{aligned}
& E-\mathrm{CC} \stackrel{h v}{\longrightarrow} 2 \mathrm{R} \cdot \\
& \mathrm{R} \cdot+\mathrm{O}_{2} \rightarrow \mathrm{ROO} . \\
& \mathrm{CH}_{2} \mathrm{~N}+\mathrm{CHOH}+2 \mathrm{ROO} \cdot+\mathrm{O}_{2} \rightarrow \mathrm{CON}(\text { amide }) \\
& \quad+\mathrm{CO}(\text { carbonyl })+\mathrm{H}_{2} \mathrm{O}(l)+2 \mathrm{ROOH}
\end{aligned}
$$

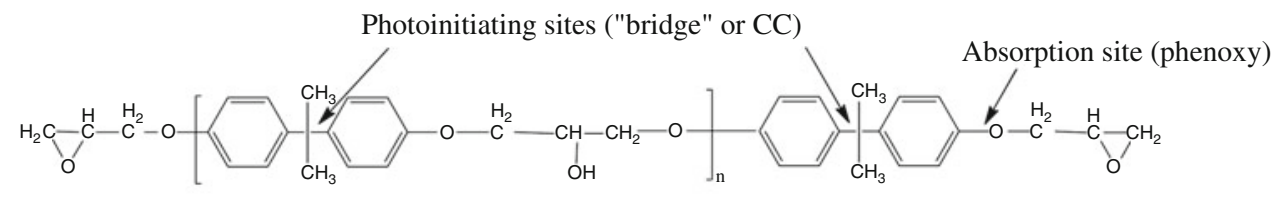

Diglycidyl ether bisphenol A epoxy
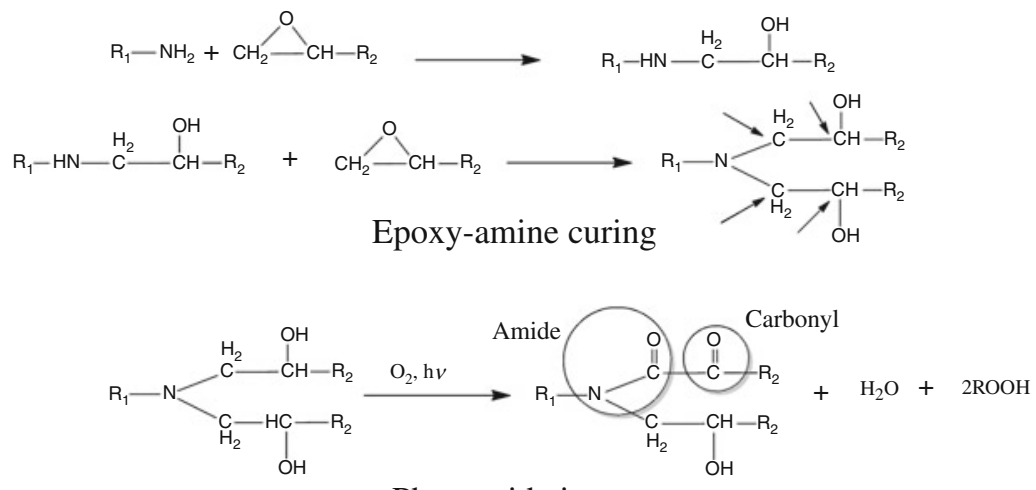

Photooxidation

Fig. 1: Schematic illustration of epoxy structure (top) and curing (middle) and photooxidation (bottom), respectively, of an epoxy-amine network. $R_{1}$ and $R_{2}$ symbolize the remaining part of the polyamine crosslinker and epoxy binder molecule, respectively. $n$ is the number of repeating units in the epoxy backbone. A three-dimensional network is formed upon full curing. The $\mathrm{CH}$-sites $\left(\mathrm{CHOH}\right.$ and $\left.\mathrm{CH}_{2} \mathrm{~N}\right)$ vulnerable to hydrogen abstraction during ultraviolet radiation exposure are indicated with arrows in the structure (middle) 
$\mathrm{R} \cdot+\mathrm{R} \cdot \rightarrow E-\mathrm{CC}$

$\mathrm{ROOH} \stackrel{h v}{\longrightarrow}$ volatile end products

where $E-C C$ is short for the "bridge" in the epoxy backbone and $\mathrm{CH}_{2} \mathrm{~N}$ and $\mathrm{CHOH}$ are the groups in the network vulnerable to hydrogen abstraction (see Fig. 1). Reactions (2), (3), and (5) are considered irreversible. Reactions (1), (2), and (4) are elementary, while reactions (3) and (5) are overall reactions. Reactions (3) and (4) are termination reactions. This reduced chemical mechanism includes the main reactions responsible for the degradation of the binder matrix without considering the many intermediate species and volatile end products involved. The initiation reaction (1) is assumed to simply break the "bridge" between the aromatic groups in the epoxy backbone (see Fig. 1). Wypich ${ }^{4}$ and others have suggested that particular chain scission reaction, but also the possibility of formation of a $\mathrm{CH}_{3}$ radical (also at the "bridge" molecular position), which does not lead to any chain scission. Furthermore, Ollier-Dureult and Bosse ${ }^{34}$ suggest that the $\mathrm{C}-\mathrm{O}$ bonding in the phenoxy structure in the epoxy can break and lead to chain scission, but these two last reactions are not included at this stage because the fractional split between the three pathways is not known. Reaction (2) is always part of a photooxidation mechanism. ${ }^{35}$ Reaction (3) is essential to include because amide and carbonyl groups are known to be formed as oxidation products in more or less equal amounts. ${ }^{28}$ Reaction (4) can, in principle, lead to other end products than reforming of the original epoxy structure. Since no such products have been observed ${ }^{28}$ and because there has not been any detection of degradation in the bulk oxygen-free part of the densely crosslinked coatings considered here, ${ }^{15}$ the radicals are assumed to simply recombine to the original bonding. Reaction (5) is shown in the mechanism, but not included in the model because the exact volatile end products formed are not known. So in the model, $\mathrm{ROOH}$ is accumulated and the concentration of ROOH simply represents volatile species that may be formed (e.g., ketones, alcohols, phenols, and methane). Branching of the free-radical mechanism by radicals formed as intermediate products in reaction (5) is neglected (no radical feedback) because there are no catalytic metal species in the coatings considered $^{1}$ (except perhaps for a later special case with nanopigments). It is assumed that there is no oxygen consumption in reaction (5). Another reaction that is often included in the chain reaction scheme is the termination reaction

$\mathrm{ROO} \cdot+\mathrm{ROO} \cdot \rightarrow \mathrm{ROOR}+\mathrm{O}_{2}$

However, there are no reports of peroxide end products being formed for epoxy-amine networks and simulations of this work, including the reaction (taking it as being elementary), revealed that a very large and unrealistic rate constant was required before the reaction had any influence on the simulation results. Therefore, it was omitted in the model.

\section{Chemical kinetics}

The chemical kinetics of reaction (1) is given by

$\left(-r_{1, \mathrm{CC}}\right)=k_{1} E_{\mathrm{r}}^{1 / 2} C_{\mathrm{CC}}$

where

$E_{\mathrm{r}}=\phi E_{l}$

$\phi$ is the quantum yield of the epoxy resin and $E_{l}$ and $E_{\mathrm{r}}$ are the radiation intensity of the transmitted light at position $l$ and the radiation intensity at position $l$ that can be used for reaction (1), respectively. The radiation intensity dependency of the rate was proposed by Christensen et al. ${ }^{36}$ The remaining kinetic expressions are assumed to be given by

$\left(-r_{2, \mathrm{O}_{2}}\right)=k_{2}[\mathrm{R} \cdot]\left[\mathrm{O}_{2}\right]$

$\left(-r_{3, \mathrm{CHOH}}\right)=k_{3}\left[\mathrm{CH}_{2} \mathrm{~N}\right]^{2}[\mathrm{CHOH}]\left[\mathrm{O}_{2}\right][\mathrm{ROO} \cdot]^{2}$

$\left(-r_{4, \mathrm{CC}}\right)=k_{4}[\mathrm{R} \cdot]^{2}$

The $\mathrm{CH}_{2} \mathrm{~N}$ concentration dependency of the rate of reaction (3) was suggested by Bellenger et al. ${ }^{30}$

\section{Mechanisms of coating degradation}

The process that takes place when a densely crosslinked epoxy-amine coating is exposed to constant UV radiation and humidity at a fixed temperature in an accelerated exposure device is schematically shown in Fig. 2. From the very beginning of an exposure test, photoinitiated chain scission reactions take place, which slowly degrade the top layer of the binder matrix. Simultaneously, if the coating, prior to exposure, has been stored at another value of relative humidity than that in the exposure chamber, moisture is absorbed (or desorbed depending on the relative humidity in the chamber) and starts to penetrate the coating. At the surface, an oxidation front begins to move into the coating. The rate of movement of this front is dependent on the rates of chemical oxidations, the solubility of oxygen in the coating, and the rate of diffusion of oxygen into the coating. When a critical fraction of the original network chains has been broken at the coating surface, the ablative front (i.e., the coating surface) starts to move and the coating thickness is reduced. After some time, the rate of movement of the oxidation and ablative fronts can 


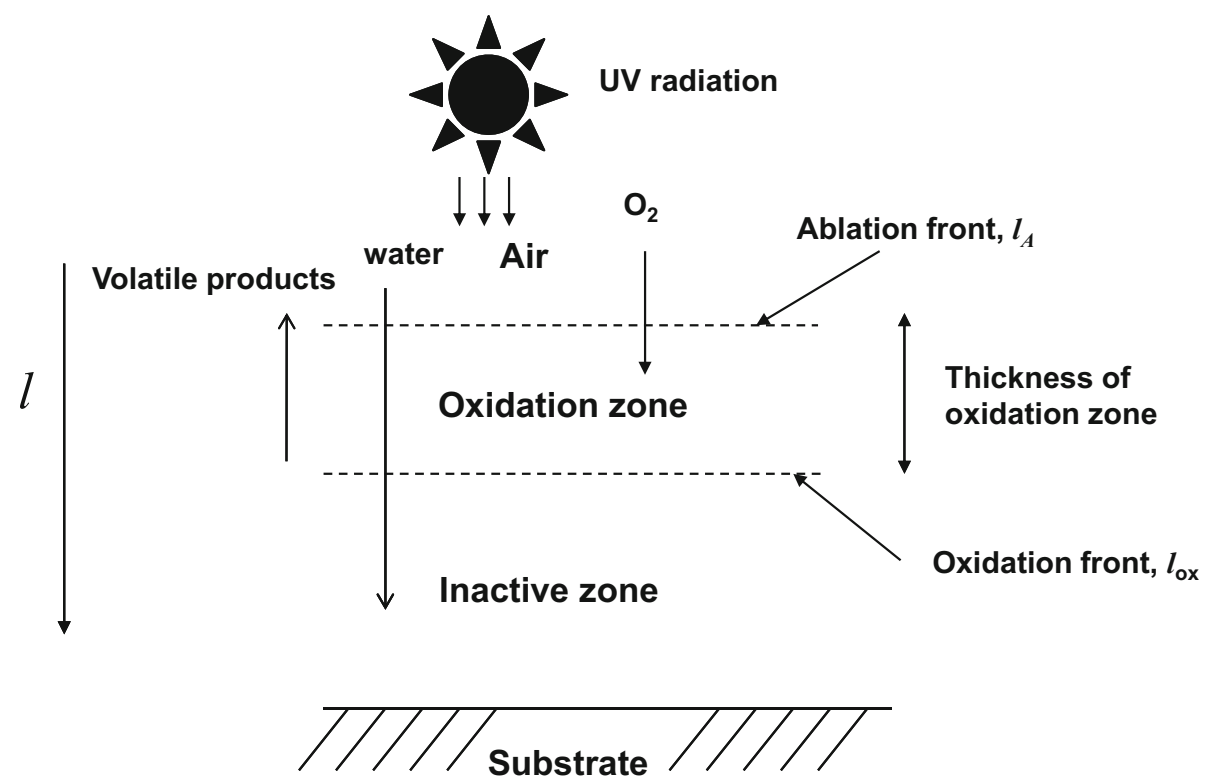

Fig. 2: Schematic illustration (cross section view) of epoxy-amine coating during exposure to ultraviolet (UV) radiation and humidity. On the surface of the coating, a thin oxidation zone is formed, where the degradation takes place. Figure is not to scale; in reality the oxidation zone is much thinner than the initial coating thickness

become equal and a stable oxidation zone thickness is established. This stable surface zone has been observed in practice for highly crosslinked coatings ${ }^{15}$ and estimated by various analytical methods to be less than and close to $2 \mu \mathrm{m}$, the actual width probably being somewhat dependent on the exposure conditions applied. ${ }^{37,38}$ In the inner, much wider and oxygen-free zone, no degradation takes place despite the fact that radiation penetrates. When radicals are formed in this zone, they rapidly recombine and no damage occurs. In the stable oxidation zone, concentration gradients are established, the original matrix structure is partly lost, and oxidation products are present. As evidenced by Nguyen et al., ${ }^{12}$ about $80 \%$ of the original benzene rings in the epoxy structure can disappear from the outer part of the oxidation zone and the presence of carbonyl and amide groups increase rapidly. Weight loss has been observed to start before the ablation front begins to move and the oxidation zone must therefore be expected to be somewhat porous, at least in the outer part.

\section{Mathematical modeling}

A transient 1-D model capable of describing degradation of densely crosslinked coating exposed to UV radiation and humidity at slightly elevated temperatures is described here. The degradation process is schematically shown in Fig. 2. The model takes into account photoinitiated chain reactions, intrafilm oxygen permeability, water absorption and diffusion, reduction of crosslink density, and development of a thin oxidation zone. The overall purpose of the model is to provide a tool that can estimate the mass loss and matrix ablation of a coating, as well as oxygen and solid phase concentration profiles in the oxidation zone at all values of time. The stable oxidation zone thickness obtained is a function of the various processes taking place and as such is treated as an output provided by the model. The following "active" groups are considered in the cured network (see Fig. 1): $\mathrm{CH}$ groups next to secondary hydroxyl $(\mathrm{CHOH})$, phenoxy groups $(\mathrm{Ph})$, "bridges" between benzene rings in the epoxy structure (CC), and $\mathrm{CH}$ groups next to tertiary amine groups in the crosslinker structure $\left(\mathrm{CH}_{2} \mathrm{~N}\right)$. Product groups formed are carbonyl, amide, and hydroperoxide. Water vapor and oxygen, which may absorb or dissolve in the coating, are also considered. The assumptions underlying the model development are:

- Exposure conditions are limited to constant air temperature, relative humidity, and UV radiation intensity. There is no visible or infrared radiation. Acid precipitation, air pollutants, aggressive dust and aerosols, and biological attacks are neglected.

- A clearcoat (completely cured and densely crosslinked network based on stoichiometric amounts of reactant functional groups) of epoxy binder and amine crosslinker is considered. There are no UV absorbers, antioxidants, or additives present in the homogeneous coating. Pigments are considered in special cases only.

- Chemical degradation is represented by reactions (1)-(5). 
- Oxidation and chain scission take place in the oxidation zone only. The rest of the coating is inactive, except for water diffusion and absorption.

- The initial coating surface is flat, nonporous, and without defects.

- The coating is isothermal and the temperature of the coating is equal to that of the chamber air temperature at all times.

- Diffusivities in the coating of all active groups are assumed to be negligible, except for $\mathrm{ROOH}$, which is assumed to be rapidly degraded to volatile and fast diffusing end products.

- The only photosensitive group in the network is phenoxy (also called phenyl ether) and it only absorbs in the interval $300-330 \mathrm{~nm}$, or, more precisely, slightly above $300 \mathrm{~nm} .^{4,28,30-33}$ As degradation proceeds, carbonyl groups are formed and phenoxy groups disappear. The UV molar absorptivities of these two groups are assumed to be the same (equal to that of carbonyl) and the concentration of the photosensitive group and the absorption capacity of the coating do not vary over time. Photoinitiating species can also be impurities or oxidation products initially present in the epoxy resin, ${ }^{1}$ but that will be neglected in this analysis.

- Moisture in the coating can influence the diffusion rate of oxygen in the oxidation zone via a lowering of the coating glass transition temperature and potential swelling of the network.

- The amount of water absorption in the coating is independent of coating degradation.

- Reflection of UV radiation at the coating-substrate interface is neglected.

- Moisture (water) does not react with the cured network structure.

- No thermal degradation takes place at the temperatures considered (maximum of $50^{\circ} \mathrm{C}$ ).

- Radiation intensity received by the coating surface corresponds to that of the lamps in the UVchamber (angle of exposure is zero degrees and distance between lamps and coatings small enough not to influence the radiation intensity).

- Internal stress in the coating is considered indirectly only via the values used for the adjustable model parameters.

- Potential skeleton breaking reactions, due to internal stress, as described by Bellenger and Verdu, ${ }^{29}$ are neglected.

- An average and thereby constant diffusion coefficient, independent of coating degradation and position, is used for liquid water. For oxygen, an average and constant diffusion coefficient in the oxidation zone is used, but the value of this parameter is dependent on coating degradation and relative humidity and must therefore be treated as an adjustable parameter of the model.

- There is no external mass transport resistance for oxygen (i.e., the intrafilm mass transport resistance is much larger than the external resistance).

- Potential formation of peracids is neglected.

- All CC and CH groups vulnerable to hydrogen abstraction react independently of one another.

- Relaxation (physical degradation) of the polymer network is neglected.

- The network formed upon curing is ideal with no loops or intramolecular bonds. ${ }^{39}$

- The ablation front starts to move when the local degree of conversion of elastically effective network chains (crosslink density) has reached a critical value, termed $X_{\mathrm{CL}, \max }$. The surface is removed by the loss of volatile photoproducts.

The validity of the above assumptions, and some additional ones to be made during the model development below, is addressed after model validation has taken place. The mathematical model can now be developed by considering a so-called control volume in the coating as the basis.

\section{Moving ablation front}

The surface of the coating starts to move when the conversion of crosslinks, $X_{\mathrm{CL}}$, reaches a specified conversion, $X_{\mathrm{CL}, \max }$. From then on the surface conversion is equal to $X_{\mathrm{CL} \text {,max }}$, and the rate of movement of the ablative front can be described by ${ }^{40}$

$\frac{d l_{\mathrm{A}}}{d t}=\frac{-\left.\left(\frac{\partial X_{\mathrm{CL}}}{\partial t}\right)\right|_{l=l_{\mathrm{A}}}}{\left(\left.\left(\frac{\partial X_{\mathrm{CL}}}{\partial l}\right)\right|_{l=l_{\mathrm{A}}}\right)_{t}}$

The initial condition is given by

$l_{\mathrm{A}}(t=0)=0$

\section{Moving oxidation front}

The oxidation zone is placed between the moving surface of the coating (ablative front) and the moving oxidation front. The rate of movement of the oxidation front, at a given value of time, can be found implicitly from a condition of zero oxygen flux at the oxidation front

$\left.\frac{\partial C_{\mathrm{O}_{2}}(l, t)}{\partial l}\right|_{l=l_{\mathrm{ox}}}=0$ 
with the initial condition given by

$l_{\text {ox }}(t=0)=0$

This front-tracking approach insures that the width of the oxidation zone remains dynamic and a function of the processes taking place in the zone. An increase in oxygen availability will widen the zone and faster oxidation reactions will narrow it.

\section{Transmission of $U V$ light}

Absorption and transmission of UV light is described by the Beer-Lambert law

$E_{l}(l)=E_{\mathrm{o}} 10^{\left(-\alpha_{\mathrm{Ph}} C_{\mathrm{PhO}} l\right)}$

where $C_{\mathrm{PhO}}$ is the initial concentration of phenoxy groups in the network and $\alpha_{\mathrm{Ph}}$ is the molar absorptivity of phenoxy groups.

\section{Balance for crosslink density and CC groups}

The concentration of elastically effective network chains, which is approximately equivalent to the concentration of $\mathrm{CC}$ groups in the epoxy backbone when $n \ll 1$ (there will be one CC group in each chain when $n=0$ ), is given by

$\left(\frac{\partial C_{\mathrm{CC}}}{\partial t}\right)_{l}=-\left(-r_{1, \mathrm{CC}}\right)+\left(-r_{4, \mathrm{CC}}\right)$

with initial condition

$C_{\mathrm{CC}}(l, t=0)=C_{\mathrm{CCO}}$

As will be shown later on, the initial crosslink density and $\mathrm{CC}$ concentration $\left(C_{\mathrm{CCO}}\right)$ are calculated based on the common definition of crosslink density.

\section{Local conversion of crosslinks}

The local conversion of crosslinks in the oxidation zone is given by

$X_{\mathrm{CL}}(l, t)=1-\frac{C_{\mathrm{CC}}}{C_{\mathrm{CCO}}}$

with initial condition

$X_{\mathrm{CL}}(l, t=0)=0$

It is assumed that up to a value of conversion of $X_{\mathrm{CL}, \max }$, no intact $\mathrm{CC}$ groups are lost with the volatiles formed and there is no effect of porosity on $C_{\mathrm{CC}}$.

The concentration profiles of the species present in the leached layer, needed in the solution of the above equations, can be determined by the mass balances presented below.

\section{Mass balance for nonvolatile compounds}

A differential mass balance for immobilized component $i$ (active groups except CC) in the coating gives

$$
\begin{aligned}
\left(\frac{\partial C_{i}}{\partial t}\right)_{l} & =-\sum_{j}\left(-r_{j, i}\right)+\left(\frac{C_{i}}{V}\right)\left(\frac{\partial V}{\partial t}\right)_{l} \\
& =-\sum_{j}\left(-r_{j, i}\right)-\left(\frac{C_{i}}{1-\varepsilon}\right)\left(\frac{\partial \varepsilon}{\partial t}\right)_{l}
\end{aligned}
$$

with initial condition

$C_{i}(l, t=0)=C_{i \mathrm{O}}$

where $t(\mathrm{~s})$ is time, $C_{i}\left(\mathrm{~mol} / \mathrm{m}^{3}\right.$ coating) is concentration of active group $i, \varepsilon$ is porosity, and $\left(-r_{i, i}\right)\left(\mathrm{mol} i / \mathrm{m}^{3}\right.$ solid coating $\mathrm{s}$ ), which is positive for reactants and negative for products, is the rate of reaction $j$ with respect to component $i$. This equation takes into account chemical reactions (first term on the right hand side) and development of porosity in the coating (second term on the right hand side), which continuously decreases the concentration of the active groups in the coating.

\section{Porosity in the oxidation zone}

The porosity of the coating at a given position in the oxidation zone is assumed to be a power law function of the fraction of crosslinks that have been broken by reaction (1)

$\varepsilon(l, t)=\left(1-\frac{C_{\mathrm{CC}}(l, t)}{C_{\mathrm{CCO}}}\right)^{\alpha}$

There is no scientific basis for this functional relationship other than it meets the requirements of a porosity of zero when no crosslinks have been broken and a porosity of unity when all crosslinks are broken. The exponent $\alpha$ must be estimated from experiments. Upon differentiation the temporal derivative is obtained:

$$
\left(\frac{\partial \varepsilon}{\partial t}\right)_{l}=\alpha\left(1-\frac{C_{\mathrm{CC}}(l, t)}{C_{\mathrm{CCO}}}\right)^{\alpha-1}\left(-\frac{1}{C_{\mathrm{CCO}}}\left(\frac{\partial C_{\mathrm{CC}}}{\partial t}\right)_{l}\right)
$$

\section{Mass balance for oxygen}

The concentration of oxygen in the solid coating in the oxidation zone is given by a differential mass balance 


$$
\begin{aligned}
\frac{\partial C_{\mathrm{O}_{2}}}{\partial t}= & \frac{\partial}{\partial l}\left[D_{\mathrm{O}_{2}} \frac{\partial C_{\mathrm{O}_{2}}}{\partial l}\right]-\left[\left(-r_{2, \mathrm{O}_{2}}\right)+\left(-r_{3, \mathrm{O}_{2}}\right)\right] \\
& -\left(\frac{C_{\mathrm{O}_{2}}}{1-\varepsilon}\right)\left(\frac{\partial \varepsilon}{\partial t}\right)_{l}
\end{aligned}
$$

with initial condition

$C_{\mathrm{O}_{2}}(l, t=0)=0$

The boundary condition at the moving oxidation front is given by

$C_{\mathrm{O}_{2}}\left(l_{\mathrm{ox}}, t\right)=0$

and at the ablation front by

$C_{\mathrm{O}_{2}}\left(l_{\mathrm{A}}, t\right)=S_{\mathrm{eq}} P_{\mathrm{O}_{2}}^{\mathrm{air}}$

where $S_{\text {eq }}$ is the solubility of oxygen in the coating.

\section{Mass balance for liquid water}

Diffusion of liquid water, $C_{\mathrm{W}}(l, t)$, in the coating is given by a differential mass balance

$\frac{\partial C_{\mathrm{W}}}{\partial t}=\frac{\partial}{\partial l}\left[D_{\mathrm{W}} \frac{\partial C_{\mathrm{W}}}{\partial l}\right]+\left(-r_{3, \mathrm{~W}}\right)$

with an initial condition

$$
C_{\mathrm{W}}(l, t=0)=C_{\mathrm{WO}}\left(\mathrm{RH}_{\mathrm{O}}\right)
$$

One boundary condition is given from no substrate penetration of water

$\left.\frac{\partial C_{\mathrm{W}}}{\partial l}\right|_{l=l_{\mathrm{o}}}=0$

and the other from an equilibrium condition

$$
C_{\mathrm{W}}\left(l=l_{\mathrm{A}}, t\right)=h(\mathrm{RH})
$$

where $h(\mathrm{RH})$ is the equilibrium water absorption in the coating at a given value of relative humidity, RH.

\section{Coating weight loss}

The relative weight loss of the coating, which initially can be positive, is given by

$$
\begin{aligned}
\frac{\Delta m}{m_{\mathrm{o}}}= & \frac{M_{\mathrm{W}, \mathrm{water}} A}{m_{\mathrm{o}}} \int_{l_{\mathrm{A}}}^{l_{\mathrm{o}}} C_{\mathrm{w}} d l-\frac{l_{\mathrm{A}} A \rho_{\mathrm{F}}}{m_{\mathrm{o}}}-\frac{A \rho_{\mathrm{F}}}{m_{\mathrm{o}}} \int_{l_{\mathrm{A}}}^{l_{\mathrm{ox}}} \varepsilon d l \\
& +\frac{A M_{\mathrm{w}, \mathrm{O}_{2}}}{m_{\mathrm{o}}} \int_{l_{\mathrm{A}}}^{l_{\mathrm{ox}}} C_{\text {carbonyl }} d l
\end{aligned}
$$

The first term on the right takes into account weight gain from water absorption, the second ablation, and the third term includes weight loss in the oxidation zone (formation of porosity due to coating degradation). Oxygen fixation to the network chains, corresponding to reaction (3), is included in the fourth term (simulations revealed that this term can in fact be neglected). The oxygen consumption in reaction (2) is released again as ROOH in reaction (3) and is therefore not included.

\section{Heat balance}

The coating can be assumed to be isothermal at all times (for an evaluation of this point see Levenspiel ${ }^{41}$ ), but the coating temperature can differ from the surrounding air temperature. The coating temperature that is obtained at given conditions can be calculated from an energy balance taking into account heat convection, radiation, and substrate conduction. ${ }^{42}$ However, in a UV-chamber, which is relevant for this work, there will be little difference between the air and coating temperatures. Croll et al. ${ }^{43}$ have measured the difference to $3^{\circ} \mathrm{C}$ for a clearcoat exposed in a UV chamber maintained at $58^{\circ} \mathrm{C}$ air temperature. Due to the fact that the heat balance requires the estimation of parameters specific to each UV testing chamber, which are typically not available, ${ }^{42}$ coating and air temperature will be assumed equal.

\section{Crosslink density}

The initial crosslink density of the cured network can be calculated from the method of Hill ${ }^{39}$ assuming an ideal network. All epoxy resin molecules (with functionality of 2) then form elastically effective network chains and if a $f_{\mathrm{PA}}$-functional amine (with $2 \cdot f_{\mathrm{PA}}$ active hydrogens) is used, then $1 \mathrm{~mol} 2 \cdot f_{\mathrm{PA}}$-functional amine hydrogens react with $f_{\mathrm{PA}}$ mol difunctional epoxy groups and the initial crosslink density is given by

$v_{\mathrm{e}}^{\mathrm{o}}=\frac{f_{\mathrm{PA}} \rho_{\mathrm{F}}}{M_{\mathrm{w}, \mathrm{PA}}+f_{\mathrm{PA}} M_{\mathrm{w}, \mathrm{E}}}$

\section{Initial concentrations of active groups}

The initial active group concentrations can be calculated from the initial crosslink density. Each chain in the network contains two $\mathrm{CH}_{2} \mathrm{~N}$ groups (one in each end) so that

$$
C_{\mathrm{CH}_{2} \mathrm{NO}}=2 v_{\mathrm{e}}^{\mathrm{o}}
$$

For each network chain, there are $(2+n)$ hydroxyl groups, where $n$ is the number of repeating units in a bisphenol A based epoxy resin 
$C_{\mathrm{CHOHO}}=v_{\mathrm{e}}^{\mathrm{o}}(2+n)$

Here, it is assumed that the hydroxyl group in the epoxy backbone can also abstract hydrogen. $n$ is usually close to zero $(0.01-0.1)$ so the assumption is not important. Furthermore,

$C_{\mathrm{CCO}}=v_{\mathrm{e}}^{\mathrm{o}}(1+n)$

and

$C_{\mathrm{PhO}}=v_{\mathrm{e}}^{\mathrm{o}}(2 n+2)$

\section{Glass transition temperature}

During UV radiation exposure, the network is broken down (crosslink density decreases) and it is expected that the glass transition temperature in the oxidation zone of the coating decreases. Croll et al. ${ }^{43}$ have shown that the glass transition temperature of an entire coating can be reduced after UV exposure. However, it is not possible to quantify this parameter due to lack of relevant data for densely crosslinked epoxy-amine systems exposed at constant UV radiation conditions. As will be shown later, constant average diffusion coefficients will be used for water and oxygen and the refinement is not needed at the present stage.

\section{Numerical solution procedure}

The model is rendered dimensionless by introduction of dimensionless variables and solved by the method of orthogonal collocation. At all times, oxygen is only present in the very thin surface oxidation layer with a zone thickness of $0.5-2 \mu \mathrm{m}$ (see later) compared with a total initial coating thickness of $50-200 \mu \mathrm{m}$. This leads to a very steep oxygen concentration gradient and the model cannot be solved by any conventional global discretization procedure without numerical problems. Consequently, the two zones of the coating are immobilized by introduction of suitable coordinate transformations. ${ }^{40}$ Using this approach, 6 and 3 interior discretization points in the oxidation and inactive zones, respectively, were needed to obtain convergence of the transient mass loss and thickness reduction simulations. Using parts of the numerical technique described in Ramachandran and Dudukovic ${ }^{44}$ and additional equation rearrangements, it was possible to derive an explicit equation for the rate of movement of the oxidation front as a function of the oxygen gradient in the oxidation zone and the rate of movement of the ablation front. To initiate calculations, a very low initial value of the position of the oxidation front $l_{\mathrm{ox}}$ has to be assigned in the following window of convergence: $10^{-5}<l_{\mathrm{ox}} / l_{\mathrm{o}}<5 \times 10^{-4}$. In addition, initial concentration profiles for oxygen and water in the oxidation zone must be assumed. Some sensitivity of the weight loss towards the initial concentration profile of oxygen used was found, but the stable dimensionless profile of oxygen was almost insensitive to the values provided so this stable profile, once obtained, could be used to initiate calculations in all cases. The pseudo-steady-state assumption (see e.g., Levenspiel ${ }^{41}$ ) was used on the radical concentrations to obtain robust simulations.

\section{Estimation of model parameters}

The model requires a number of physical and chemical constants as inputs. These were estimated from various literature sources and are listed in Table 1 . In the "Sensitivity analysis" section, the required precision of relevant parameters is evaluated. The values obtained were from similar, but not identical and nonexposed epoxy-amine networks. With aging time, the epoxyamine network is broken down by chain scissions and oxidation products are formed. This may obviously lead to changes in the parameter values in the oxidation zone, but such an added complexity is presently avoided due to lack of data.

The relationship between relative humidity $(\mathrm{RH})$ of the air and equilibrium water content in an epoxyamine network can be calculated from ${ }^{45}$

$h=h_{\mathrm{m}} \frac{k \cdot f \cdot \mathrm{RH}}{(1-f \cdot \mathrm{RH})[1+(k-1) \cdot f \cdot \mathrm{RH}]}$

where $h$ ( $\mathrm{g}$ water/100 $\mathrm{g}$ dry sample) is the percentage of water content in the specimen. In the equation, $h_{\mathrm{m}}=0.57, k=6.5, \quad$ and $f=0.76$. According to Maggana and Pissis, $h$ can be assumed independent of temperature and the correlation can also be used for

Table 1: Physical and chemical parameter values needed for the mathematical model

Parameter

Parameter values

\begin{tabular}{ll}
\hline$D_{\text {water }}{ }^{46,47}$ & $2.1 \times 10^{-12} \mathrm{~m}^{2} / \mathrm{s}\left(50^{\circ} \mathrm{C}\right)^{\mathrm{a}}$ \\
$\rho_{\mathrm{F}}$ & $1170 \mathrm{~kg} / \mathrm{m}^{3}$ \\
Spectral sensitivity & $300-330 \mathrm{~nm}$ \\
$\alpha_{\mathrm{Ph}}(310 \mathrm{~nm})$ & $1 \mathrm{~m} / \mathrm{mol}$ \\
$E_{1}-E_{4}$ & $27 \mathrm{~kJ} / \mathrm{mol}$ \\
$C_{\text {wo }}(75 \% \mathrm{RH})$ & $1.19 \times 10^{-2} \mathrm{~g}$ water $/(\mathrm{g}$ dry coating $)$ \\
& $=774 \mathrm{~mol}$ water $/\left(\mathrm{m}^{3}\right.$ dry coating $)$ \\
$\phi$ & $10^{-4}$ \\
$S_{\text {eq }}{ }^{27}$ & $1.6 \times 10^{-4} \mathrm{~mol} /\left(\mathrm{m}^{3} \text { coating Pa }\right)^{\mathrm{a}}$ \\
$k_{2}$ & $15 \mathrm{~L} / \mathrm{mol} \mathrm{s}^{2}\left(25^{\circ} \mathrm{C}\right)$ \\
$k_{3}{ }_{P_{\text {oxygen }}}^{\text {air }}$ & $>1\left(\mathrm{~m}^{3} / \mathrm{mol}^{5} \mathrm{~s}\left(25^{\circ} \mathrm{C}\right)\right.$ \\
& $21278 \mathrm{~Pa}(21 \mathrm{vol} . \%$ in air $)$
\end{tabular}

If no temperature is indicated, the parameter is assumed temperature-independent

a Standard deviation not available 
immersion of the coating system in water (heavy rainfall) corresponding to $100 \%$ relative humidity. The diffusion coefficient of water in an epoxy/amine clearcoat can be calculated from an Arrhenius expression:

$D_{\text {water }}=D_{\text {o,water }} \exp \left(-\frac{E_{\text {water }}}{R T}\right)$

with an approximate activation energy of $45 \mathrm{~kJ} / \mathrm{mol}^{46}$ and a preexponential factor of $3.86 \times 10^{-5} \mathrm{~m}^{2} / \mathrm{s}$. The value obtained for the diffusion coefficient is in good agreement with the value for an epoxy-anhydride system (clearcoat), which is $3.67 \times 10^{-13} \mathrm{~m}^{2} / \mathrm{s}$ at $25^{\circ} \mathrm{C}$ and $75 \%$ relative humidity. ${ }^{47}$ The molar absorptivity of phenoxy groups was assumed to be equal to that of carbonyl groups at $310 \mathrm{~nm}$ and taken from Schulz. ${ }^{1}$ A quantum yield value for the epoxy resin was estimated from Bellenger and Verdu. ${ }^{29,31,32}$ Quantum yield can be a function of moisture content, coating thickness, and many other parameters, ${ }^{19,48}$ but that complexity is not included in the model.

A typical network density was taken from Monney et al. ${ }^{15}$ and the spectral sensitivity from Wypych. ${ }^{4}$ An order of magnitude value for the rate constant $k_{2}$ was found in Bateman ${ }^{49}$ who estimated $k_{2}$ to 3-50 $\mathrm{L} /(\mathrm{mol} \mathrm{s})$ at $25^{\circ} \mathrm{C}$ for two different polymers (ethyl linoleate and digernyl). It seems reasonable to assume, at least as a first approximation, that the rate of oxidation of radicals could be similar in different systems and the value provided in Table 1 is used. All amine groups that react are assumed to form amides in reaction (3) and therefore $k_{3}$ should just be above a critical value (provided in Table 1).

Rate constants at a given temperature can be calculated from the following equation based on Arrhenius expressions

$\ln \left(\frac{k_{i}(T)}{k_{i}\left(T_{\mathrm{o}}\right)}\right)=\frac{E_{i}}{R}\left(\frac{1}{T_{\mathrm{o}}}-\frac{1}{T}\right)$

For later comparison, oxygen diffusion $\left(20-120^{\circ} \mathrm{C}\right)$, in an aromatic amine crosslinked epoxy network below $T_{\mathrm{g}}$, is given by ${ }^{27}$

$D_{\text {oxygen }}=D_{\text {o,oxygen }} \exp \left(-\frac{E_{\text {oxygen }}}{R T}\right)$

where the preexponential factor is $2.1 \times 10^{-10} \mathrm{~m}^{2} / \mathrm{s}$ and the activation energy is $18 \mathrm{~kJ} / \mathrm{mol}$. The solubility of oxygen in the same epoxy-amine system, $S_{\text {eq }}$, can be assumed independent of temperature $\left(20-120^{\circ} \mathrm{C}\right)$ and is assumed to be independent of relative humidity. It is generally found that for light gases, such as oxygen, the diffusivity varies a great deal more from polymer to polymer than solubility. Activation energies of all chemical reactions are assumed to be the same and equal to some intermediate value of the numbers suggested by Bellinger et al. ${ }^{30}$ Activation energies are also discussed in Bauer. ${ }^{50}$ Estimation of the remaining model parameters $\left(k_{1}, k_{4}, X_{\mathrm{CL}, \max }\right.$, and $\left.D_{\text {oxygen }}\right)$ is discussed in the "Results and discussion" section.

\section{Results and discussion}

To verify the coating degradation model, three independent experimental series of data with epoxy-amine coatings were used. Many exposure and formulation variables are required for model input and these are not always explicitly stated in the experimental reports. In general, it has been particularly difficult to establish the radiation intensity (in $\mathrm{W} / \mathrm{m}^{2}$ ) of the lamps applied in the accelerated weathering devices, the distance between lamps and coating samples in the chambers (UV radiation intensity decreases rapidly with distance), and the fractional effect delivered in the region of spectral sensitivity of epoxy-amine systems. This does not prevent simulations because the uncertainty (including that of the quantum yield) is simply lumped into the values used for $k_{1}$ (see equation 7). However, it means that the values reported for $k_{1}$ do not represent numbers for the true rate constant and as such, for purposes other than the present model, should be used with caution.

\section{Model verification using the data of Nguyen et al. ${ }^{12}$ (clearcoat)}

The first set of data was recently reported by Nguyen et al. ${ }^{12}$ who used the SPHERE equipment at NIST for experimentation, which provides very controlled exposure conditions. This appears to be the only data set available in the literature that includes both the rate of mass loss and end product formation (carbonyl). In addition, the required test parameters, air chamber temperature, relative humidity, total UV radiation intensity, initial weight of coating sample, binder molecular weights and functionalities, and coating surface area exposed, are provided. The initial dry film thickness, for a given coating, can be calculated from the following equation (assuming a nonporous coating)

$l_{\mathrm{o}}=\frac{m_{\mathrm{o}}}{A \rho_{\mathrm{F}}}$

Based on the spectral output from the SPHERE, provided in Chin et al., ${ }^{51}$ it is estimated that in the interval of spectral sensitivity of epoxies, $300-330 \mathrm{~nm}^{4}$, about $30 \mathrm{~W} / \mathrm{m}^{2}$ falls on the coatings exposed. In Fig. 3 a comparison of simulations and experimental data are shown for a clearcoat. A reasonable good agreement can be seen for the rate of mass loss. The model parameters $k_{1}, k_{4}, X_{\mathrm{CL}, \max }, D_{\text {oxygen }}$, and $\alpha$ were adjusted (values provided in the figure caption) to 
match the data points. All other parameters were estimated independently. In the first few days, due to water absorption, the mass of the coating increases. The oxidation zone becomes somewhat porous when it degrades and therefore mass loss also starts from the very beginning, but for some days the water absorption is larger than the material loss. After about 6 days, the crosslink density at the surface has decreased, corresponding to a conversion value of $X_{\mathrm{CL} \text {,max }}$, and the coating surface (ablation front) now starts to move, rapidly leading to a larger, but constant, rate of mass loss, dominated by the rate of ablation. From this point and onwards, the rate of mass loss will no longer change. In the experimental data in Fig. 3, after most of the water absorption has taken place, there is a sudden decrease in the mass of the coating, much larger than the model suggests, followed by a more or less constant weight for some days. The experimental data are based on five replicates ${ }^{12}$ so the effect should be significant and cannot be attributed to, e.g., a random loss of a "large" material piece from the oxidation zone. It has not been possible to find a physical explanation for this observation and for some unknown reason, it is not present in the other two data sets of Nguyen et al. (to be discussed later). An alternative explanation could be an instrumental or operator error in the measurements, but this has not been confirmed.

In the top part of Fig. 3, the decrease in the surface concentration of epoxy "bridges" and the increase in the surface concentration of carbonyl end product are shown. Note that here simulations and experimental data can only be compared qualitatively because the experimental data are presented as a relative change in FTIR intensity (reflection mode) in the top surface layer (down to a depth of somewhere between 0.5 and $2 \mu \mathrm{m},{ }^{12}$ the depth of penetration being frequency dependent ${ }^{52}$ ). However, it can be seen that the simulated time it takes for the end product concentration to reach a stable value is in very good agreement with the experimental data (error bars are not shown, but the experimental uncertainty is quite small ${ }^{20}$ ). Nguyen et al. have also measured the transient decrease in the relative change of FTIR intensity of benzene rings, which form part of the epoxy backbone structure. Assuming a linear relationship between FTIR signal and concentration, the benzene concentration in the top layer decreases by a factor of five in the first about 10 days $^{12}$ (not shown here). This observation cannot be compared directly to simulations, but as shown in Fig. 3, the dimensionless surface concentration of epoxy "bridges" $\left(y_{\mathrm{CC}}\right)$ decreases by $40 \%$ in the first 10 days. The relationship between the dimensionless concentration of elastically effective network chains $\left(y_{\mathrm{CC}}\right)$ and the loss of benzene rings is unknown, but it seems possible that a $40 \%$ decrease in the crosslink density at the surface can lead to a reduction of $80 \%$ in the benzene concentration in the surface layer. For soft epoxy systems, Mailhot et al. ${ }^{53}$ have found an almost complete loss of aromatic

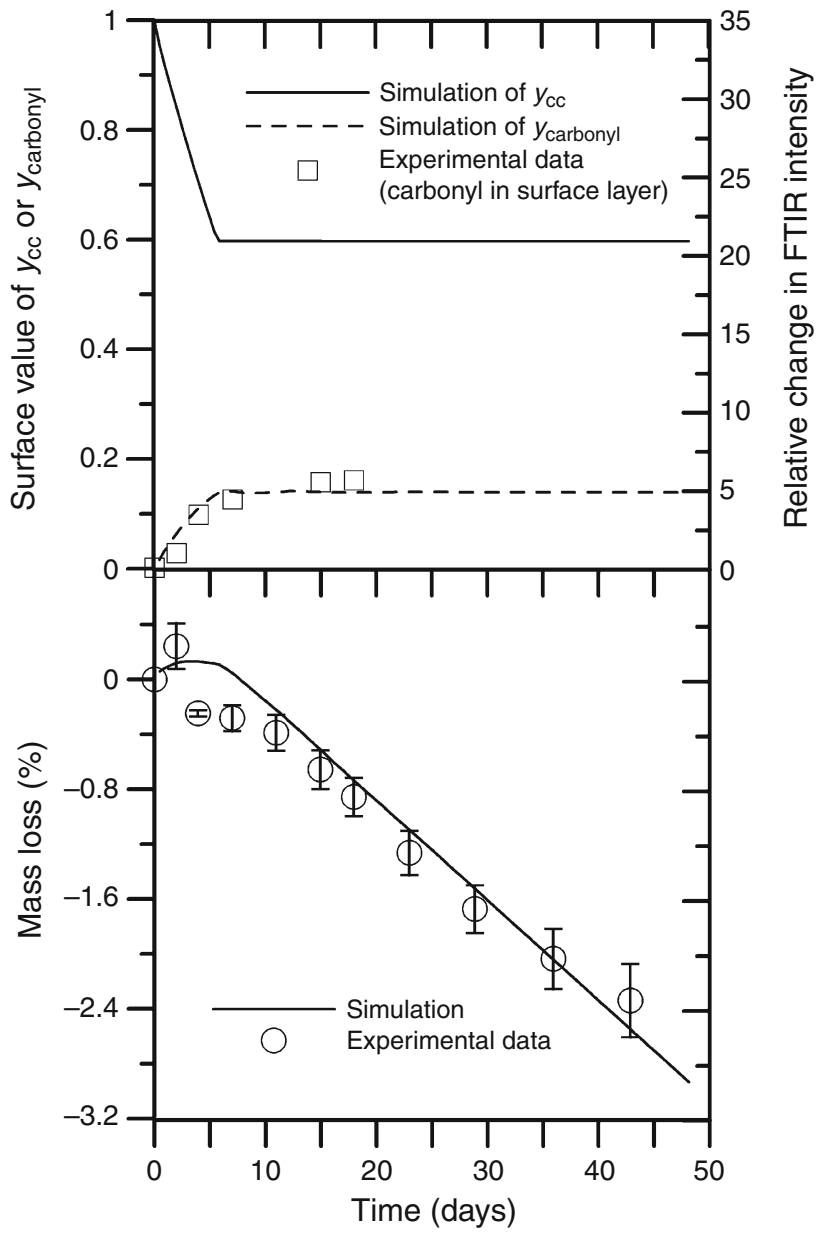

Fig. 3: Comparison of model simulations (lines) with experimental mass loss data (symbols) for a pigment-free epoxy-amine coating. Error bars are also shown on bottom plot. The experimental data were taken from Nguyen et al. ${ }^{12}$ Conditions are: $T=50^{\circ} \mathrm{C}, \mathrm{RH}=\mathbf{7 5} \%, \mathbf{R H}_{\mathrm{o}}=\mathbf{4 5} \%, E_{\mathrm{o}}=\mathbf{4 8 0}$ $\mathrm{W} / \mathrm{m}^{2} \quad(295-400 \mathrm{~nm}), E_{\mathrm{o}, \mathrm{s}}=30 \mathrm{~W} / \mathrm{m}^{2}, \quad r=1, I_{\mathrm{o}}=147 \mu \mathrm{m}$ $\left(m_{\mathrm{o}}=106.78 \mathrm{mg}\right), n=0.1, M_{\mathrm{w}, \mathrm{E}}=378 \mathrm{~g} / \mathrm{mol}, f_{\mathrm{E}}=2, M_{\mathrm{w}, \mathrm{PA}}=$ $486 \mathrm{~g} / \mathrm{mol}, f_{\mathrm{PA}}=3$ (equivalent to six active hydrogens), $m_{\mathrm{o}}=106.78 \mathrm{mg}, A=6.25 \times 10^{-4} \mathrm{~m}^{2}, \quad v_{\mathrm{e}}^{\circ}=2167 \mathrm{~mol} / \mathrm{m}^{3}$, $C_{\mathrm{CCO}}=2383 \mathrm{~mol} / \mathrm{m}^{3}, C_{\mathrm{CHOHO}}=C_{\mathrm{CH}_{2} \mathrm{NO}}=4333 \mathrm{~mol} / \mathrm{m}^{3}$, and $C_{\mathrm{PhO}}=4767 \mathrm{~mol} / \mathrm{m}^{3}$. Adjustable parameters at $50^{\circ} \mathrm{C}$ are: $X_{\mathrm{CL}, \max }=0.4, k_{1}=0.012\left(\mathrm{~m}^{2} / \mathrm{W}\right)^{1 / 2} \mathrm{~s}^{-1}, k_{4}=0.3\left(\mathrm{~m}^{3} / \mathrm{mol} \mathrm{s}\right)$, $D_{\text {oxygen }}=0.49 \times 10^{-13} \mathrm{~m}^{2} / \mathrm{s}$, and $\alpha=0.6$. The remaining parameters are provided in Table 1

character in the surface layer. In Fig. 4 simulations of the transient developments in the oxidation zone thickness and position of the oxidation and ablation fronts, still at the conditions of Fig. 3, are shown. The gap between the positions of the two fronts corresponds to the oxidation zone thickness. It can be seen that after about 10 days of exposure, a stable thickness of approximately $1.95 \mu \mathrm{m}$ is predicted by the model. This is in very good agreement with measurements done by Monney et al. ${ }^{15,26,37,38}$ using several independent analytical techniques on densely crosslinked epoxyamine coatings exposed to UV radiation. Monney 


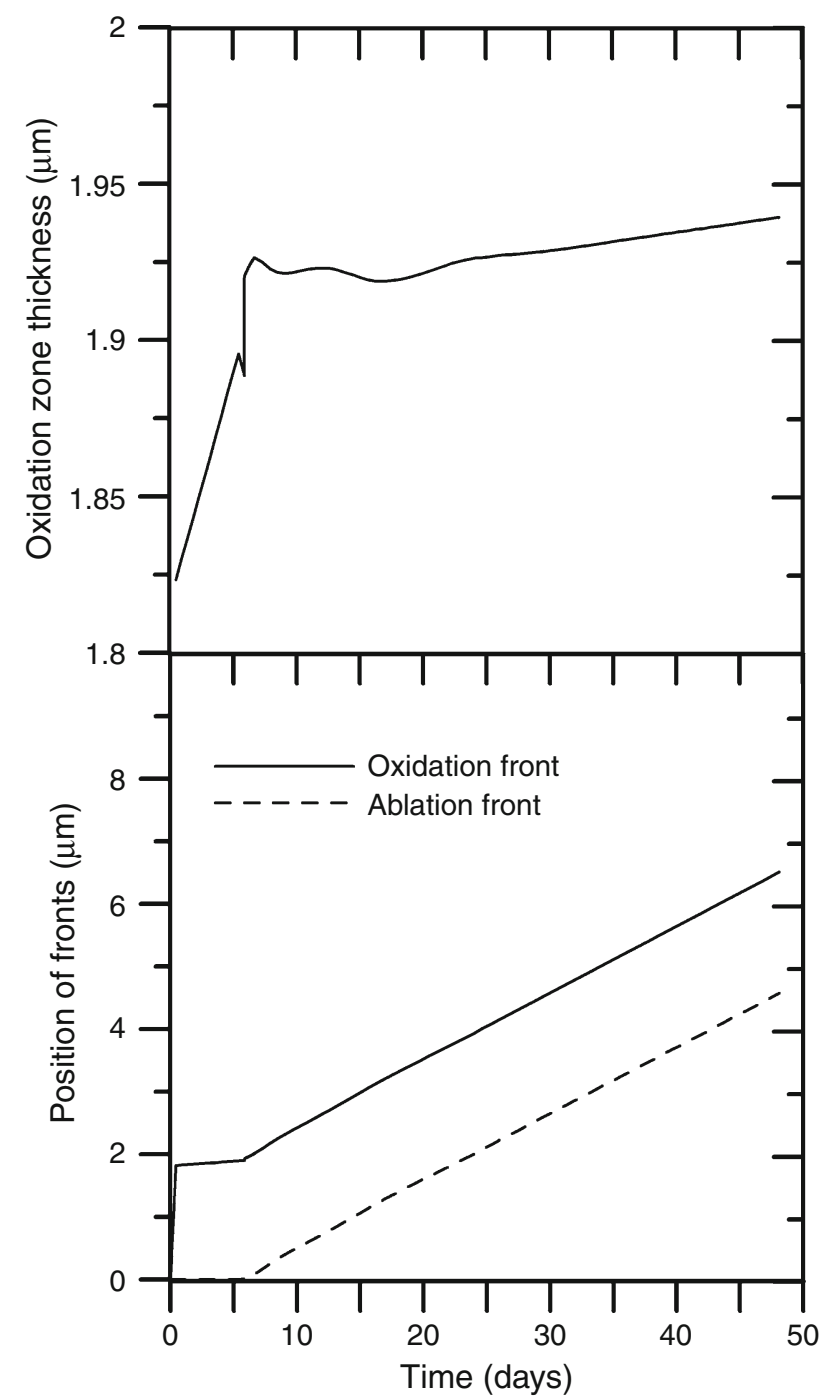

Fig. 4: Transient simulations of oxidation zone thickness (top) and positions of moving fronts (bottom) for a pigmentfree epoxy-amine coating. Conditions and parameters are the same as in the figure caption of Fig. 3

et al., for the conditions selected, found that the thickness should be close to and less than about $2 \mu \mathrm{m}$. Floyd ${ }^{25}$ suggests, based on conference discussions, that the thickness may be down to about $1 \mu \mathrm{m}$. It can also be seen in Fig. 4 that there is a lag time (about 6 days) before the ablation front begins to move. The reason for this is that a certain amount of the network (epoxy chains) must be broken before the surface is sufficiently degraded to initiate movement. A similar behavior, for other binder types and under very different exposure conditions, has been observed for underwater degradation of self-polishing antifouling coatings. ${ }^{54}$ As will be shown later, the ablation lag time of Figs. 3 and 4 has also been found in practice. The rate of movement of the oxidation front is dramatically increased when the ablation front begins to move. The reason for this is that the diffusion length of oxygen is kept constant and low, when the stable oxidation zone thickness is established.

\section{Evaluation of adjustable parameters used}

The values of the adjustable parameters used in the simulations of Figs. 3 and 4 should be accompanied by some discussion. The rate constants, $k_{1}$ and $k_{4}$, both belonging to the photoinitiating reaction (1), which is considered to be reversible, are very specific for the system considered. Uncertainties in the quantum yield and radiation intensity are lumped into $k_{1}$ and the values used cannot meaningfully be compared with values found in other studies (if these were available, so far none have been identified). The value of $\alpha$, which is related to the porosity development, is purely empirical (see equation 23), and only has an influence on the mass loss in the initial period preceding the stable mass loss period. $X_{\mathrm{CL} \text {,max }}$, the conversion of elastically effective network chains at which the ablation front begins to move, is a very important parameter as shown in the "Sensitivity analysis" section. It has not been possible to verify the value used for $X_{\mathrm{CL} \text {,max }}(0.4)$, but it seems likely that it may be dependent on, e.g., rain because Monney et al. ${ }^{15}$ suggest that ablation can be severely increased by rainfalls. The value used for the average diffusion coefficient of oxygen in the oxidation zone was $0.49 \times 10^{-13} \mathrm{~m}^{2} / \mathrm{s}\left(50^{\circ} \mathrm{C}\right)$. This number can be compared with the value, $2.47 \times 10^{-13}$ $\mathrm{m}^{2} / \mathrm{s}\left(50^{\circ} \mathrm{C}\right)$, measured by Colin et al. ${ }^{27}$ for a nonexposed, pigment-free epoxy-amine coating with a glass transition temperature of $210^{\circ} \mathrm{C}$. The binder system, though epoxy-amine, is quite different to that of Nguyen et al., but because both systems are far below their glass transition temperatures, the values might be expected to be somewhat similar. ${ }^{47}$ However, a serious complication is that the network present in the oxidation zone is quite different from that of the nonexposed binder matrix. ${ }^{55}$ Part of the epoxy backbone structure is gone and oxidation products are present. The diffusion coefficient of oxygen in the oxidation zone is most likely a strong function of position because the porosity is high at the very outer surface $^{13,56}$ and, in the model, falls to zero at the oxidation front. Possibly, the oxidation zone is only porous in the outer part-the low oxygen diffusion coefficient used in the model is an indication of this-but investigations are needed to quantify the hypothesis. If porosity is neglected completely in the model, a substantially less good fit for the mass loss in the first 10 days or so is found. Equilibrium water absorption and oxygen solubility could also be different. It is not known how these changes will influence the rate of oxygen diffusion, but Mailhot et al ${ }^{52,53}$ have found that some oxidation products can be in liquid or solid form and be likely to generate a viscous layer, the properties of which are unknown. Rivaton et al. ${ }^{55}$ even measured an almost $40 \%$ decrease in the rate of oxygen permeability after only $10 \mathrm{~h}$ UV radiation 
exposure. In addition, the uncertainty of the diffusion parameters and the relative humidity employed during the experiments have not been reported by Colin et al. ${ }^{27}$ The value used for the oxygen solubility could also be inaccurate. Seubert et al. ${ }^{57}$ found that oxygen solubility in UV-curable urethane acrylate clearcoats was dependent on the curing conditions. So, it can be concluded that the value used for the diffusion coefficient is presently the right order of magnitude, but somewhat low compared with expectations. One reason could be that there is an oxygen consumption taking place that has not been accounted for. This was tested by assuming that for each mole $\mathrm{ROOH}$ degraded in reaction (5), $\beta$ moles of oxygen is consumed. However, when using the diffusion coefficient provided by Colin et al., ${ }^{27}$ it was only possible to get a good fit if $\beta=5$ and this oxygen consumption seems very high, though it cannot be ruled out as a possibility before a precise value for the diffusion coefficient becomes available. Yet, it is, in principle, possible in this way to use $\beta$ instead of $D_{\text {oxygen }}$ as an adjustable parameter.

\section{Model verification using the data of Nguyen et al. ${ }^{12}$ (nano-pigmented systems)}

Nguyen et al. have also measured the effect of nanoparticles on the degradation behavior. In Fig. 5, comparisons of simulations and experimental data for two low-pigmented coatings are shown. One of the coatings contains $0.72 \mathrm{wt} \%$ multiwalled carbon nanotubes (MWCNT) and the other $5 \mathrm{wt} \%$ nano- $\mathrm{SiO}_{2}$. A good agreement between simulations and experimental data is evident. For the coating containing nano- $\mathrm{SiO}_{2}$, all adjustable parameters were the same as for the clearcoat in Fig. 3 and the difference in the relative mass loss (and associated ablation rates) can be attributed entirely to a difference in the initial dry film thickness (the small compositional effect on initial crosslink and coating density is negligible). On the other hand, the rate of mass loss for the coating containing MWCNT is smaller than that of the clearcoat. The constant rate of ablation (not shown) is reduced by $36 \%$ when the coating contains as little as $0.72 \mathrm{wt} \% \mathrm{MWCNT}$. The effect of MWCNT is thought to be mechanical though the material can most likely also absorb UV radiation, similar to carbon black, but the concentration is rather low for a strong absorption effect (for nano- $\mathrm{ZnO}, 1-4 \mathrm{wt} \%$ is required ${ }^{58}$ ). Aglan et al. ${ }^{59}$ have shown that as little as $0.1 \mathrm{wt} \%$ MWCNT can improve the cohesiveness of an epoxy coating. Both hypotheses were tried by varying the values of radiation intensity, $E_{\mathrm{o}}$, and conversion of elastically effective network chains where ablation sets in, $X_{\mathrm{CL} \text {,max }}$. Though a reasonable fit could be obtained by decreasing $E_{\mathrm{o}}$, corresponding to less radicals being formed in reaction (1), the curvature was not quite as the experimental data suggests it should be. Increasing $X_{\mathrm{CL} \text {,max }}$ from 0.4 to 0.6 , on the other hand, resulted in

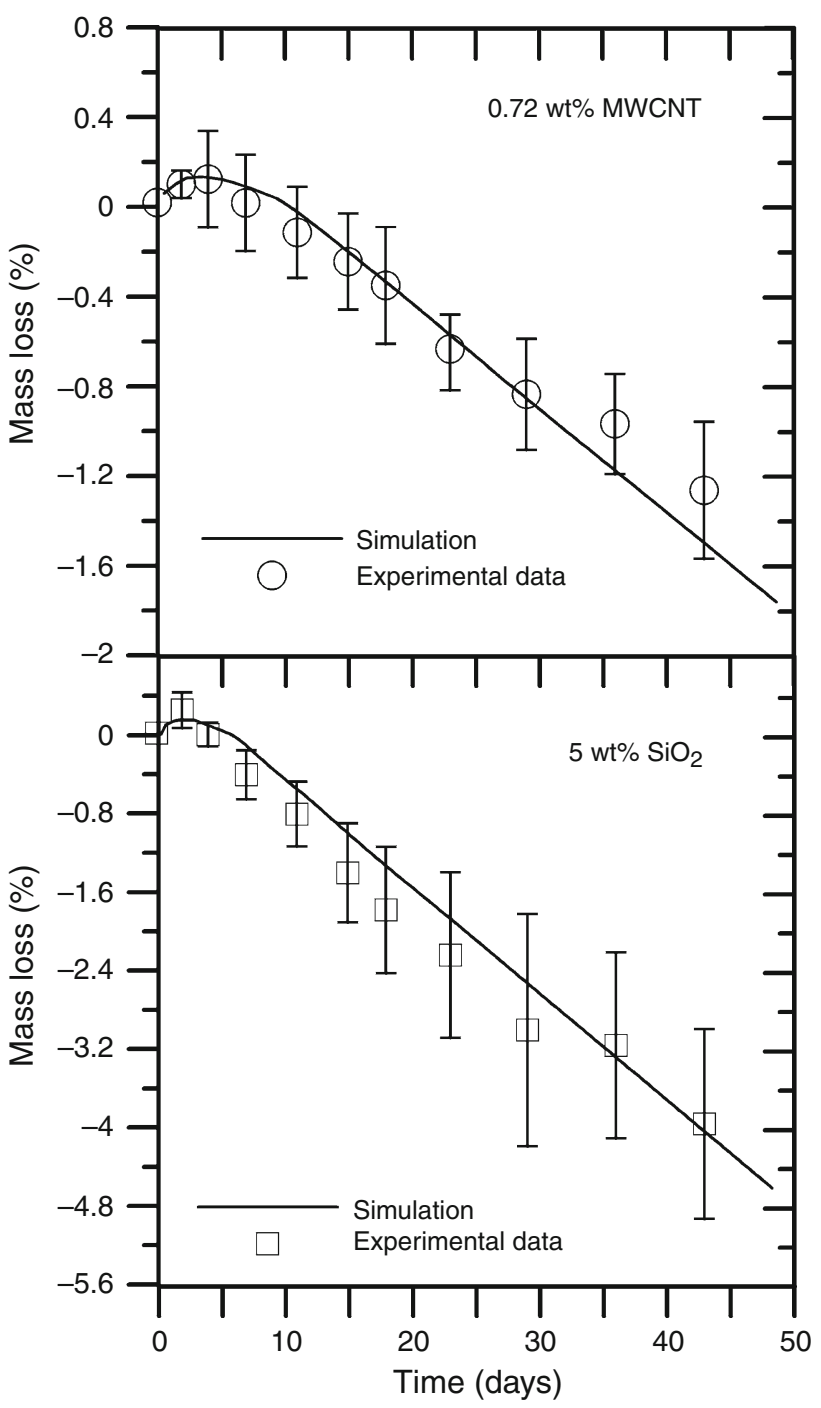

Fig. 5: Comparison of model simulations (lines) with experimental mass loss data (symbols) of an epoxy-amine coating containing either $\mathbf{0 . 7 2}$ wt $\%$ multiwalled carbon nanotubes (MWCNT) or $5 \mathrm{wt} \%$ nano-SiO $\mathrm{S}_{2}$ particles. Error bars are also shown. The experimental data were taken from Nguyen et al. ${ }^{12}$ Conditions are the same as in the figure caption of Fig. 3 except for the initial dry film thickness, which was $146 \mu \mathrm{m}$ for MWCNT $\left(m_{0}=106.16 \mathrm{mg}\right)$ and $95 \mu \mathrm{m}$ for nano-SiO $\mathrm{S}_{2}\left(m_{0}=72.27 \mathrm{mg}\right)$, respectively. Adjustable parameters are the same as in Fig. 3 except the parameter $X_{\mathrm{CL}, \max }$, which is $\mathbf{0 . 6}$ for the coating with MWCNT. The remaining parameters are provided in Table 1

the very good fit shown in Fig. 5 suggesting that the effect of MWCNT is mostly mechanical (an increase in $X_{\mathrm{CL}, \max }$ means that more bonds must be broken before ablation sets in).

Contrary to the clearcoat data in Fig. 3, where a rapid mass loss rate is observed after 2-3 days, the pigmented systems in Fig. 5 exhibit a more smooth transition, which the model can predict very well. The thickness of the stable oxidation zone is $1.96 \mu \mathrm{m}$ in the top figure and $1.97 \mu \mathrm{m}$ in the bottom figure. 


\section{Concentration profiles in the oxidation zone and entire coating}

Concentration profiles, at times where the rate of movement of the fronts have become constant (i.e., a stable oxidation zone thickness has been established), are shown in Fig. 6. It can be seen that the radical concentrations are very low and that there is a large drop in oxygen concentration from the ablation to the oxidation front. The carbonyl concentration is highest at the ablation front and falls to zero at the oxidation front. On the contrary, the crosslink density is lowest at the ablation front and equal to that of the nonexposed coating at the oxidation front. The porosity is $58 \%$ at the ablation front and falls to zero at the oxidation front (not shown). The radiation intensity is practically constant over the thin oxidation zone (not shown).

Oxygen and water concentration profiles in the entire coating, at two values of time, are shown in Fig. 7 (note that coating thickness decreases over time due to ablation). The oxygen profiles, due to rapid oxidation reactions, are very steep (practically vertical) at all times. Water, in liquid form, rapidly diffuses into the entire coating and saturates it within 1-2 days. Due to relative humidity $\left(\mathrm{RH}_{\mathrm{O}}=45 \%\right)$ in the room where the coating was placed prior to UV exposure, the coating already contains some water at $t=0$, where the dimensionless concentration is unity. Following the water absorption (or desorption under other conditions) is important because the oxygen diffusion rate into the coating is a function of the glass transition temperature, which again depends on the water concentration. ${ }^{1}$

\section{Model verification using the data of Rezig et al. ${ }^{13}$ (clearcoat)}

When validating a mathematical model it is best to use several independent sets of experimental data to challenge the model. In the present case, another set of exposure data, using a Xenon lamp with filters (removing most infrared and some visible radiation), was published by Rezig et al. ${ }^{13}$ and are very useful as a supplement because ablation rates, as opposed to mass loss data, were measured. In Fig. 8 a comparison of simulations and experimental data for an epoxy-amine coating at a relative humidity of $75 \%$ is shown. It can be seen that the model can predict the experimental data very well using adjustable parameters not very different from those used in the simulations of Fig. 3. Again it should be noticed that the comparison in the top figure can only be qualitative because absorbance (in transmission mode) only, and not absolute concentration, is available. A very important prediction is the lag time of about 10 days before the ablation front starts to move. As discussed earlier on, this is the time it takes to break a certain fraction of the elastically effective network chains on the coating surface. Monney et al. $^{38}$ have also found an experimental lag

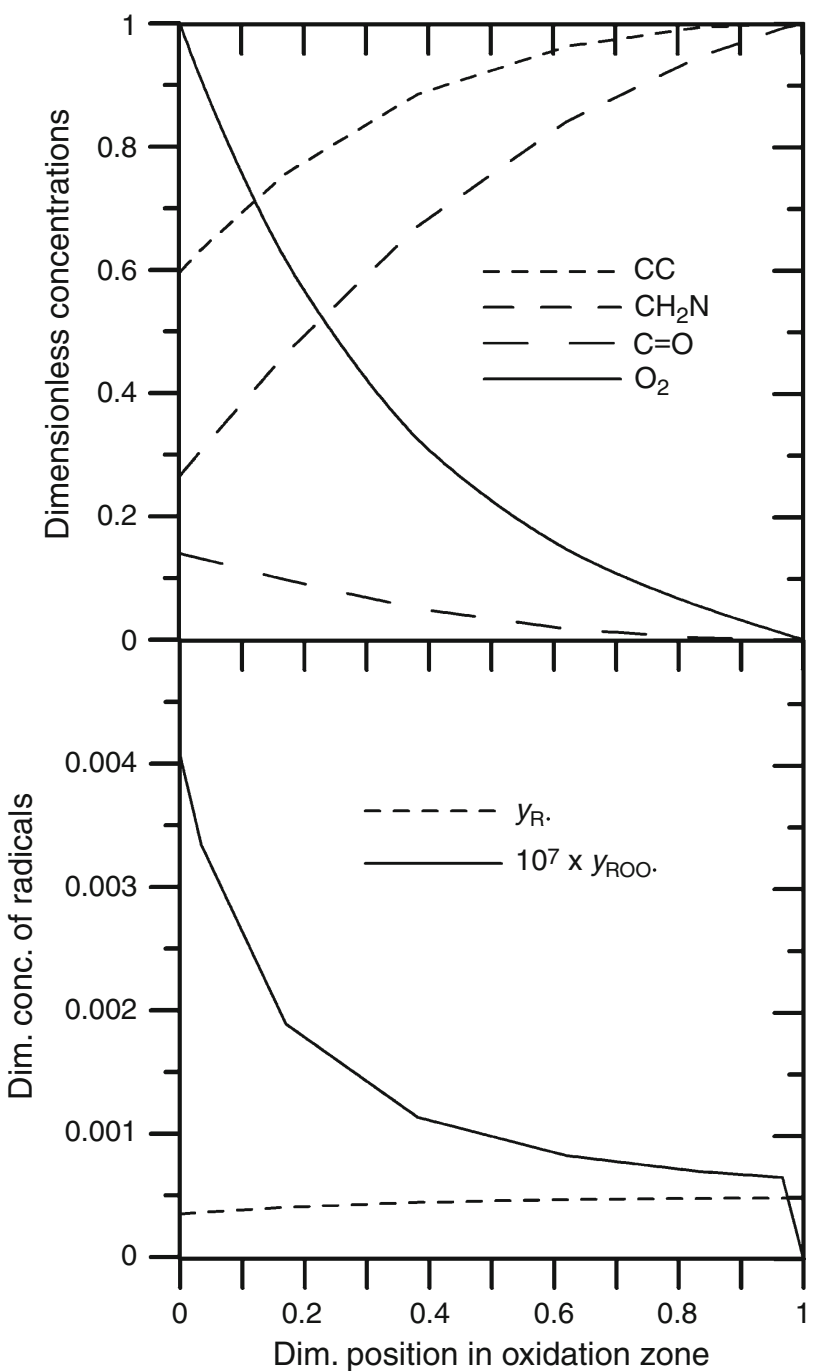

Fig. 6: Stable (i.e., at times larger than about 20 days) dimensionless concentration profiles in the oxidation zone. Dimensionless concentrations are defined as $C_{i} / C_{i 0}$, where $C_{i 0}$ (initial concentration) for a given component, $i$, is provided in the caption of Fig. 3. For the two radicals, $C_{i \mathrm{O}}=C_{\mathrm{Pho}}$ and for oxygen $C_{i \mathrm{O}}=3.4 \mathrm{~mol} / \mathrm{m}^{3}$ coating. Note the additional scaling by a factor of $10^{7}$ for ROO. The thickness of the stable oxidation zone is close to $2 \mu \mathrm{m}$ (see Fig. 4). Conditions and parameters are the same as in the caption of Fig. 3

time of about 10 days under similar conditions. The thickness of the stable oxidation zone, under the conditions of Fig. 8, is estimated by the model to 1 $\mu \mathrm{m}$. The ablation rate corresponding to Fig. 3 is 3.3 times higher than that of Fig. 8. Temperature and relative humidity are the same in the two experiments, so the difference found is due to a higher initial crosslink density in Fig. 8, some variation in mechanical properties $\left(X_{\mathrm{CL} \text {,max }}\right)$, and differences in the rate of reaction (1) and in the rate of oxygen diffusion.

Exposure data for the same coating system as in Fig. 8 , but for a relative humidity of only $9 \%$, is shown 


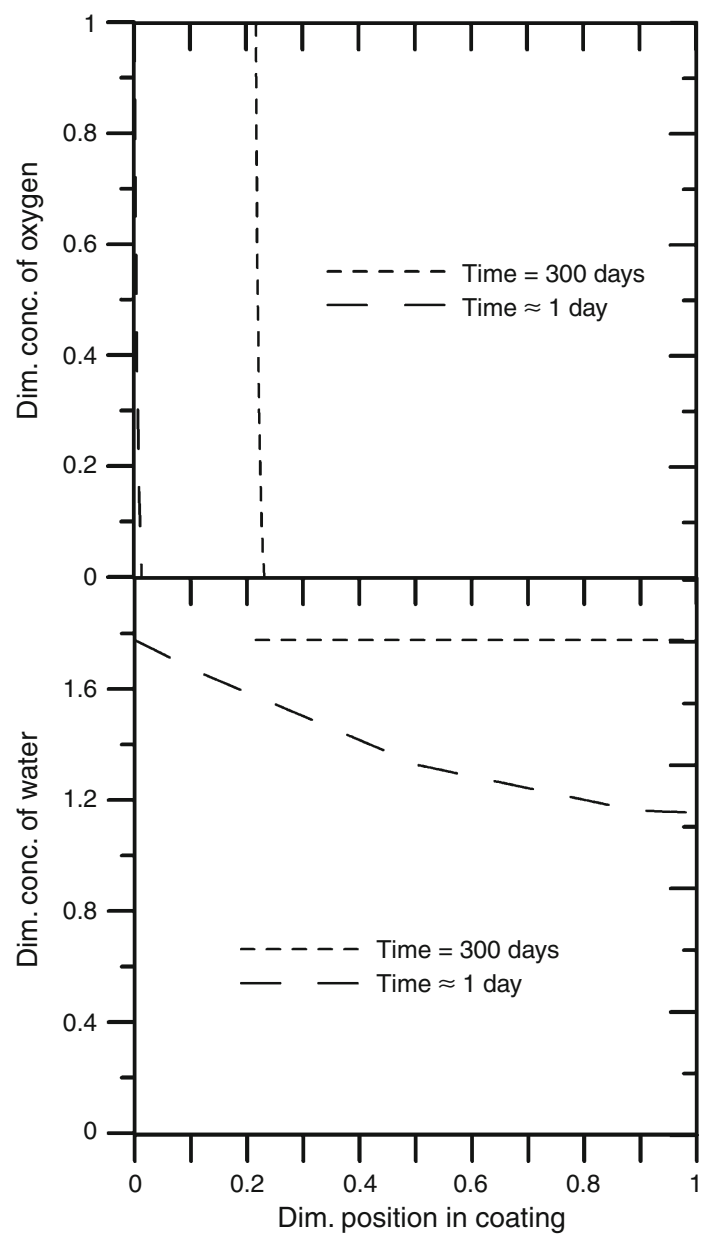

Fig. 7: Dimensionless water and oxygen concentration profiles as a function of dimensionless position in the coating during UV radiation exposure. Dimensionless concentrations are defined as $C_{j} / C_{i 0}$, where $C_{\text {wo }}$ is given in Table 1 and for oxygen $C_{i \mathrm{O}}=3.4 \mathrm{~mol} / \mathrm{m}^{3}$ coating. Dimensionless position is defined as $I / I_{\mathrm{o}}$. At $t=0$, the dimensionless water concentration is unity throughout the coating corresponding to $\mathrm{RH}_{\mathrm{o}}=45 \%$. Conditions and parameters are the same as in the caption of Fig. 3

in Fig. 9. The stable rate of ablation is reduced by more than $50 \%$ by this change in relative humidity. According to Schulz, ${ }^{1}$ this could be due to a lowering of the oxygen diffusion coefficient because of a change in the glass transition temperature of the coating with changes in relative humidity (see also Shi and $\mathrm{Croll}^{60}$ ). Perera and Eynde ${ }^{61}$ have measured the $T_{\mathrm{g}}$ of an epoxy-amine network and found that it may increase from about $45^{\circ} \mathrm{C}$ at $\mathrm{RH}=75 \%$ to about $80^{\circ} \mathrm{C}$ at $\mathrm{RH}=9$ vol. \%, so the effect can be large. Slight swelling of the matrix may also take place at high values of relative humidity, ${ }^{47}$ which will be absent at $\mathrm{RH}=9$ vol.\%. As can be seen in Fig. 9, the model is able to match the experimental data within the experimental uncertainties. The only model parameter that has been changed from Fig. 8 to Fig. 9 is the diffusion coefficient of oxygen in the oxidation zone,

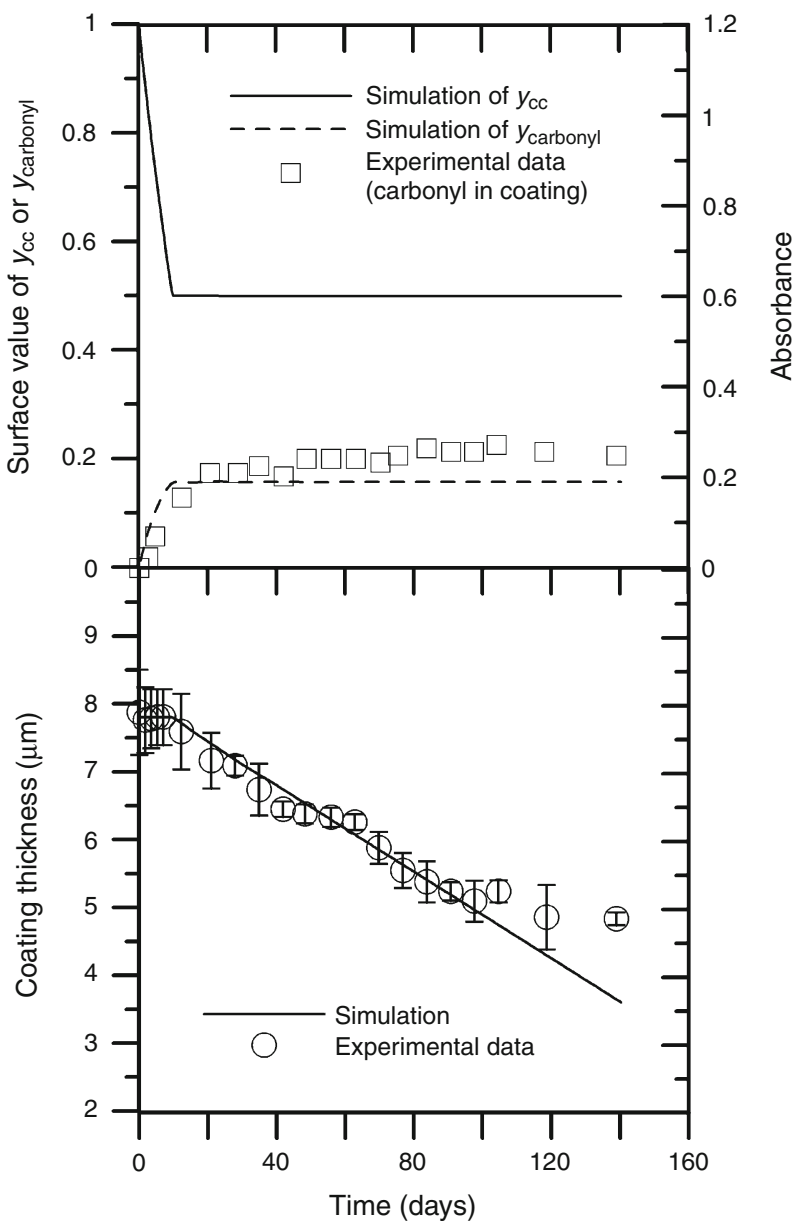

Fig. 8: Comparison of model simulations (lines) with experimental thickness reduction data (symbols) of a pigment-free epoxy-amine coating at a high value of relative humidity. The experimental data were taken from Rezig et al. ${ }^{13}$ Conditions are: $T=50^{\circ} \mathrm{C}, \mathrm{RH}=75 \%$, Xenon lamp (300-800 nm) with filters removing most infrared and some visible radiation, $E_{o, s}=50 \mathrm{~W} / \mathrm{m}^{2}, r=1, I_{0}=7.8 \mu \mathrm{m}$, $\mathrm{n}=0.1, M_{\mathrm{w}, \mathrm{E}}=344 \mathrm{~g} / \mathrm{mol}, f_{\mathrm{E}}=2, M_{\mathrm{w}, \mathrm{PA}}=142.2 \mathrm{~g} / \mathrm{mol}, f_{\mathrm{PA}}=$ 2, $\quad v_{\mathrm{e}}^{\mathrm{o}}=2819 \mathrm{~mol} / \mathrm{m}^{3}, \quad c_{\mathrm{CCO}}=3100 \mathrm{~mol} / \mathrm{m}^{3}, \quad c_{\mathrm{CHOHO}}=$ $C_{\mathrm{CH}_{2} \mathrm{NO}}=5637 \mathrm{~mol} / \mathrm{m}^{3}$, and $C_{\mathrm{PhO}}=6201 \mathrm{~mol} / \mathrm{m}^{3}$. Adjustable parameters at $50^{\circ} \mathrm{C}$ are: $X_{\mathrm{CL}, \max }=0.5, \quad k_{1}=0.007\left(\mathrm{~m}^{2} /\right.$ W) ${ }^{1 / 2} \mathrm{~s}^{-1}, k_{4}=0.3\left(\mathrm{~m}^{3} / \mathrm{mol} \mathrm{s}\right), D_{\text {oxygen }}=0.12 \times 10^{-13} \mathrm{~m}^{2} / \mathrm{s}$, and $\alpha=0.6$

which was lowered by a factor of 4.8. It is important to notice that this change does not affect the ablation lag time predicted, which experimental data shows is about 10 days in both Figs. 8 and 9. As will be shown in the "Sensitivity analysis" section, changing other adjustable parameters than the oxygen diffusion coefficient to lower the ablation rate is always accompanied by a reduction also in the lag time, which experimental data in Figs. 8 and 9 clearly shows is not right. This supports the glass transition temperature effect on the oxygen diffusion coefficient reported by Schulz ${ }^{1}$ and others. The thickness of the stable oxidation zone, under the conditions of Fig. 9, is estimated by the model to 


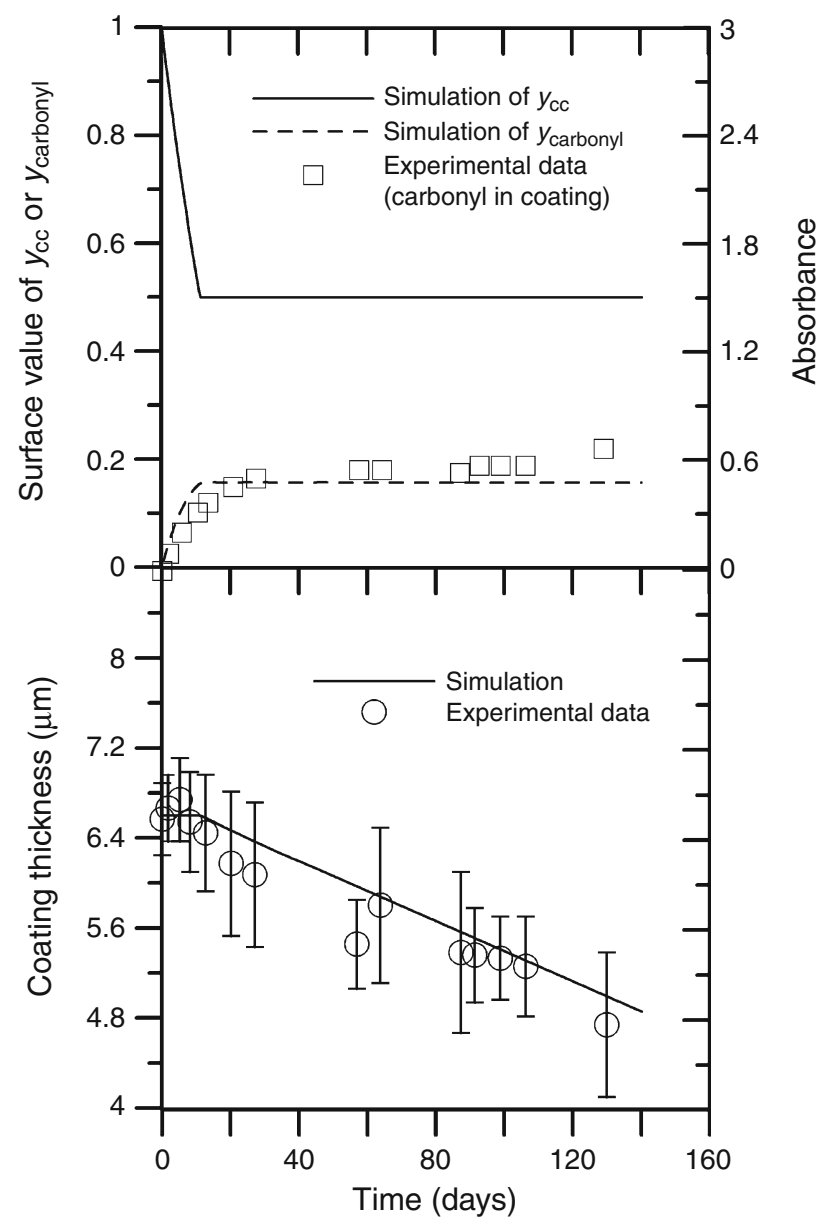

Fig. 9: Comparison of model simulations (lines) with experimental thickness reduction data (symbols) of a pigment-free epoxy-amine coating at a low value of relative humidity. The experimental data were taken from Rezig et al. $^{13}$ Conditions are the same as in Fig. 8 except the relative humidity which is only $9 \%$ and the initial coating thickness which is $6.6 \mu \mathrm{m}$. All parameter values are the same as in Fig. 8 except $D_{\text {oxygen, which is } 0.025 \times 10^{-13}}$ $\mathrm{m}^{2} / \mathrm{s}\left(50^{\circ} \mathrm{C}\right)$

$0.5 \mu \mathrm{m}$. The oxidation zone thickness is determined by the relative movements of the two fronts and in this case, the lower oxygen diffusion coefficient makes the oxidation front move more slowly relative to that of the ablation front (which in fact also moves slower). The rate of movement of the ablation front is strongly coupled to the rate of movement of the oxidation front and the ablation front can never overtake the oxidation front.

\section{Model verification using the data of Guillot et al. ${ }^{14}$ (clearcoat)}

The last experimental data set is taken from Guillot et al. ${ }^{14}$ who studied the ablation of a pigment-free epoxy-amine coating during exposure by a Xenon lamp with filters that remove infrared radiation.
Unfortunately, the relative humidity during exposure is not provided. In Fig. 10 a comparison between simulations and experimental data is shown. The model is able to predict the ablation rate and the expected ablation lag time using the adjustable parameters provided in the figure caption. The ablation rate is about $10 \%$ lower than that corresponding to the data in Fig. 3. The thickness of the stable oxidation zone, under the conditions of Fig. 9, is estimated by the model to $1.25 \mu \mathrm{m}$.

\section{Sensitivity analysis}

A sensitivity analysis of the model with respect to important parameters was performed under the conditions of Fig. 3. Each parameter was varied around the estimated value used in the simulations of Fig. 3 and the movement of the ablation front was used as model output. The ablation rate is not a function of the value of $\alpha$ and therefore it is not considered. First, the effect of oxygen solubility and diffusivity can be seen in Fig. 11. It is apparent that the stable ablation rate is sensitive to both parameters, in particular the oxygen solubility. However, the lag time, preceding the movement of the ablation front, is only sensitive to the oxygen solubility, where it varies from 3.2 to 11.3 days in Fig. 11 (top). This dependency is seen because an increase in oxygen solubility increases the rate of oxidation at the coating surface, where the coating is always saturated with oxygen. On the other hand, an increased rate of oxygen diffusion only increases the rate of oxidation within the oxidation zone and not at the surface, where saturation is always maintained due to the absence of any external mass transport resistance of oxygen.

In Fig. 12 the effects of the rate constants $k_{1}$ and $k_{2}$ on the stable ablation rate and lag time are shown. The model is sensitive to both parameters because they control the rate of photoinitiation and rate of radical oxidation. A literature value for $k_{2}$ was used in this work for all simulations, but it has not been confirmed that it can be used for all radical oxidations. Both parameters affect the rate of oxidation, also at the coating surface, and therefore the lag time dependency is seen. The effect of $k_{4}$ on simulations is the same as that of $k_{1}$ as long as $k_{3}$ has a high value (not shown).

Finally, the effect of $X_{\mathrm{CL} \text {,max }}$ is shown in Fig. 13. Also for this parameter, a model dependency on both the stable ablation rate and lag time is seen. $X_{\mathrm{CL} \text { max }}$ is expected to be dependent on humidity, especially rain, and probably also internal stress or other phenomena that influence the mechanical properties of the oxidation zone. Misovski et al. ${ }^{62}$ and Monney et al. ${ }^{15}$ have reported that the ablation rate of a coating can be increased when it rains due to washing away of photodegradation products.

A last point to note is that since the effect of the rate constants and $X_{\mathrm{CL} \text {,max }}$ (and oxygen solubility for that matter) on the ablation rate are quite similar, it means 


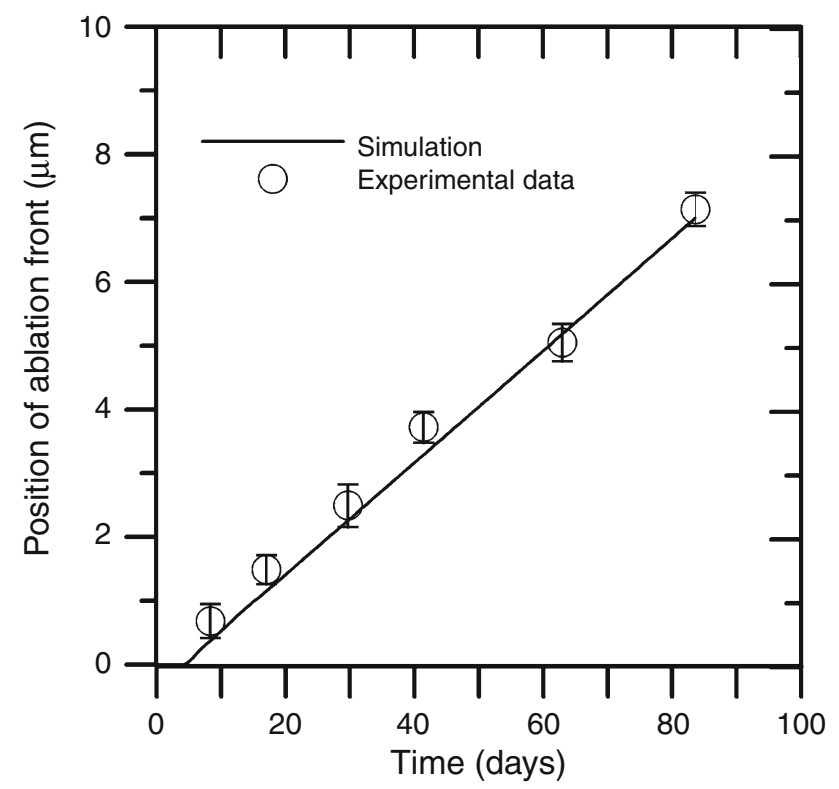

Fig. 10: Comparison of model simulations (lines) with experimental thickness reduction data (symbols) of a pigment-free epoxy-amine coating. The experimental data were taken from Guillot et al. ${ }^{14}$ Conditions are: $T=44^{\circ} \mathrm{C}$, RH = unknown, Xenon lamp with filters $(300-800 \mathrm{~nm})$, $E_{\mathrm{o}, \mathrm{S}}=5 \mathrm{~W} / \mathrm{m}^{2}$ (assumed), $r=1, n=0.1, M_{\mathrm{w}, \mathrm{E}}=390 \mathrm{~g} / \mathrm{mol}$, $f_{\mathrm{E}}=2, \mathrm{M}_{\mathrm{w}, \mathrm{PA}}=170 \mathrm{~g} / \mathrm{mol}, f_{\mathrm{PA}}=2$ (equivalent to four active hydrogens), $\quad v_{\mathrm{e}}^{\circ}=2463 \mathrm{~mol} / \mathrm{m}^{3}, \quad C_{\mathrm{CCO}}=2709 \mathrm{~mol} / \mathrm{m}^{3}$, $C_{\mathrm{CHOHO}}=C_{\mathrm{CH}_{2} \mathrm{NO}}=4926 \mathrm{~mol} / \mathrm{m}^{3}$, and $C_{\mathrm{PhO}}=5419 \mathrm{~mol} / \mathrm{m}^{3}$. Adjustable parameters at $44^{\circ} \mathrm{C}$ are: $X_{\mathrm{CL}, \max }=0.3, k_{1}=0.036$ $\left(\mathrm{m}^{2} / \mathrm{W}\right)^{1 / 2} \mathrm{~s}^{-1}, k_{4}=0.25\left(\mathrm{~m}^{3} / \mathrm{mol} \mathrm{s}\right), D_{\text {oxygen }}=0.22 \times 10^{-13}$ $\mathrm{m}^{2} / \mathrm{s}$, and $\alpha=0.6$

that more than one combination of the adjustable parameters will fit the data (small changes in one parameter can be counteracted by small changes in another parameter). Therefore, the rate constants are not "true" rate constants. Larger data sets are needed for obtaining accurate values.

\section{Analysis of rate phenomena potentially influencing the oxidation zone thickness}

It was shown in the preceding sensitivity analysis that the ablation rate and to some extent the ablation lag time are dependent on the oxygen solubility and diffusion coefficient in the oxidation zone, the various rate constants, and the conversion of crosslinks at the ablation front. This means that the overall rate of degradation and the thickness of the oxidation zone are influenced by oxygen permeability (i.e., solubility and diffusion coefficient), radical generation, and radical oxidation because all three rate processes influence the degradation behavior. An interesting question in relation to this that needs further discussion is whether the thickness of the oxidation zone is determined mainly by a lack of UV radiation or of oxygen at the oxidation front. In the model of this

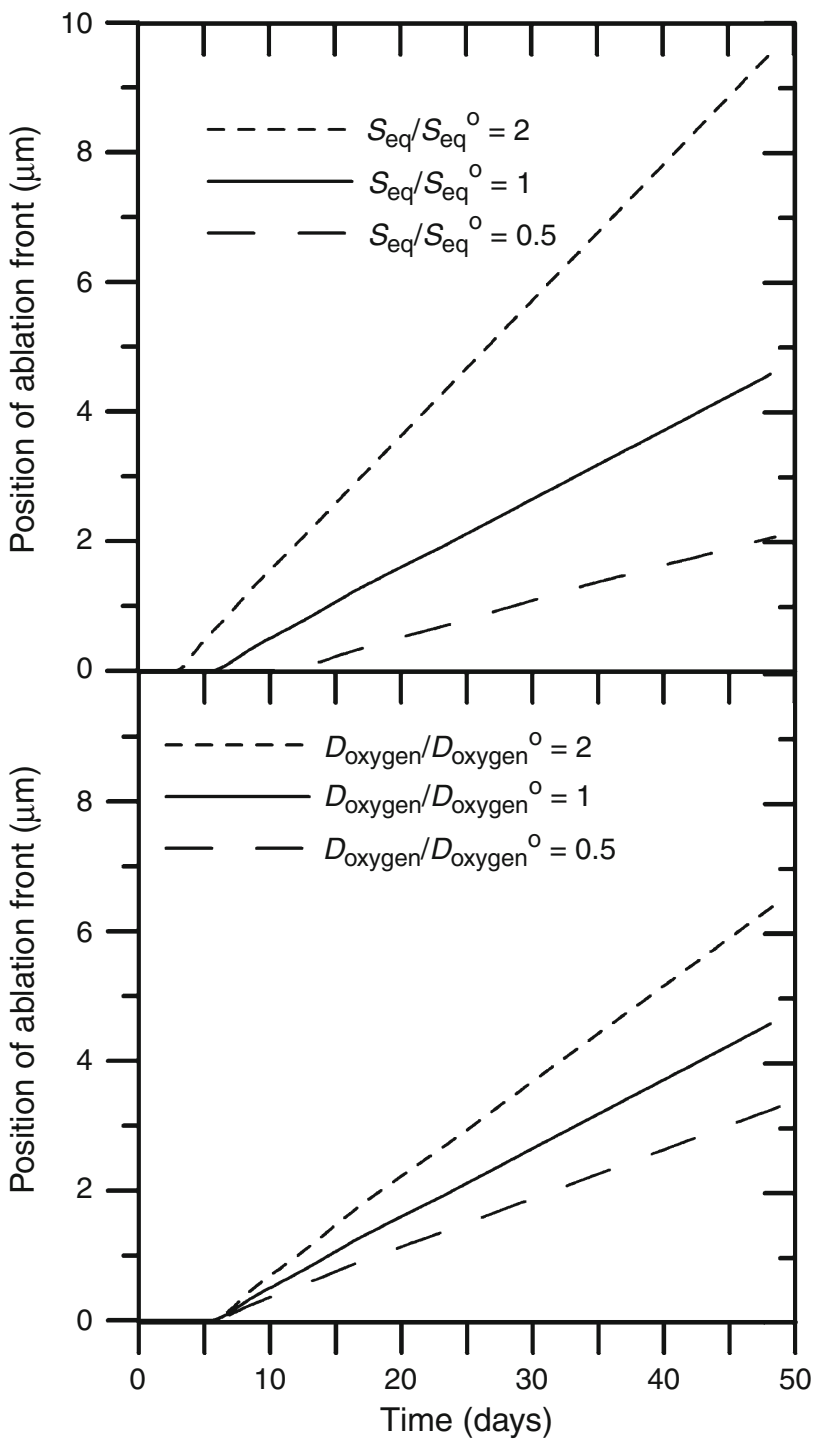

Fig. 11: Sensitivity plot with respect to oxygen solubility and diffusion coefficient in a pigment-free epoxy-amine coating. Conditions and parameters (except the one in the legend) are the same as in the caption of Fig. 3. When the parameter value in the legend is equal to unity, it corresponds to the simulation in Fig. 3. The stable thickness of the oxidation zone varies from 1.91 to $2.02 \mu \mathrm{m}$ in the top plot (highest thickness for largest value of $S_{\text {eq }}$ ) and from 1.37 to $2.72 \mu \mathrm{m}$ in the bottom plot (highest thickness for largest value of $D_{\text {oxygen }}$ )

work, it was assumed that the concentration of oxygen is negligible at the oxidation front and that there is no oxygen present in the bulk coating, only in the oxidation zone. However, an alternative assumption could be that there is an abundance of oxygen in the coating and that the UV radiation intensity is close to zero at the oxidation front. Both these assumptions may, in principle, lead to a thin surface oxidation zone. If both oxygen and UV radiation are present in the bulk of the coating then the oxidation zone would 


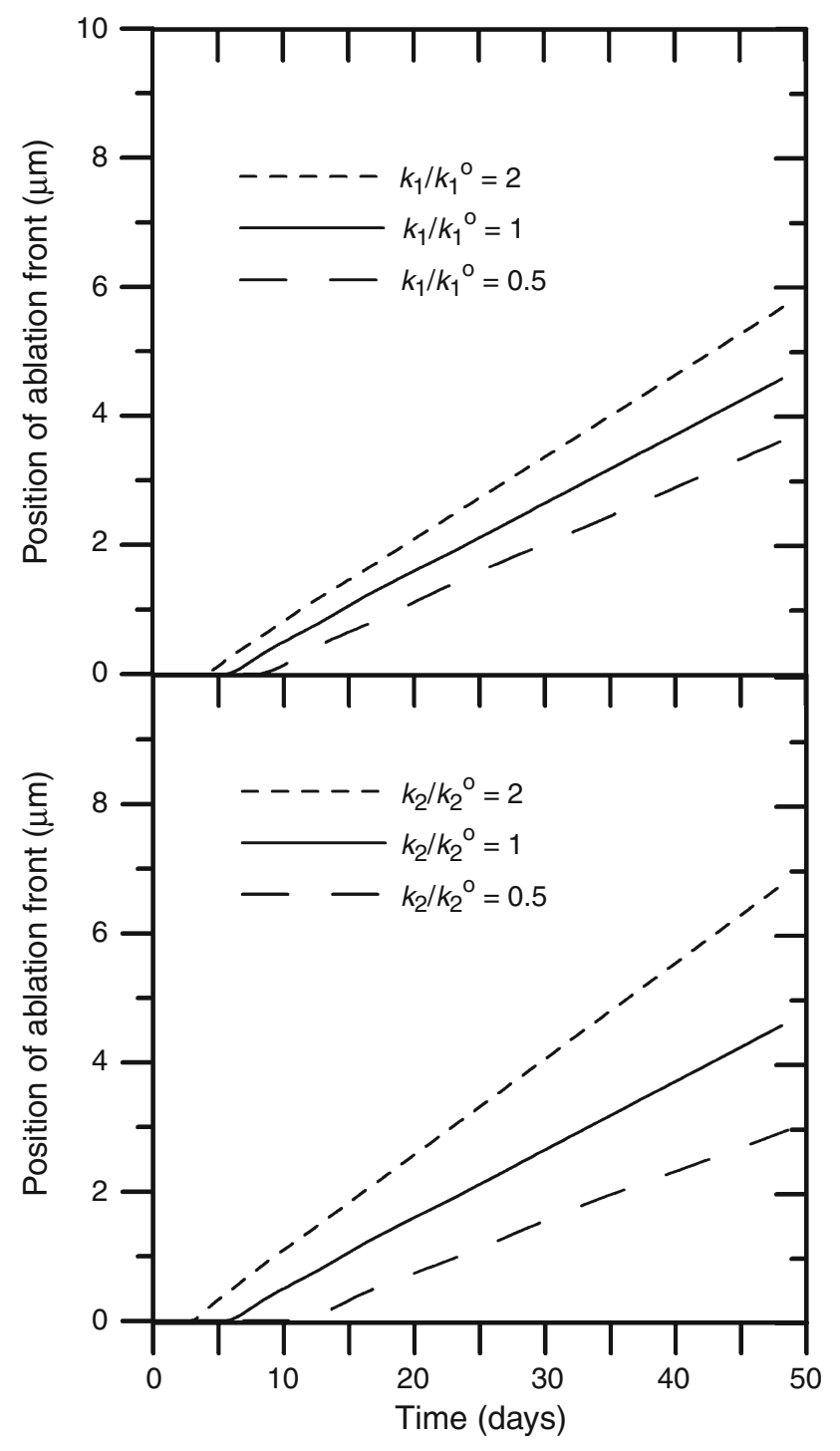

Fig. 12: Sensitivity plot with respect to $k_{1}$ and $k_{2}$ in a pigment-free epoxy-amine coating. Conditions and parameters (except the one in the legend) are the same as in the caption of Fig. 3. When the parameter value in the legend is equal to unity, it corresponds to the simulation in Fig. 3. The stable thickness of the oxidation zone varies from 1.64 to $2.30 \mu \mathrm{m}$ in the top plot (highest thickness for lowest value of $k_{1}$ ) and from 1.41 to $2.71 \mu \mathrm{m}$ in the bottom plot (highest thickness for lowest value of $k_{2}$ )

extend over most of, or even the entire, coating, which is not in agreement with experimental data for the coating systems considered. It has been demonstrated by various methods (e.g., IR-ATR spectroscopy, ${ }^{38}$ X-ray analysis with EDS, ${ }^{37}$ and nano-indentation ${ }^{63}$ ) that the oxidation zone thickness in densely crosslinked epoxy coatings, with high glass transition temperatures, exposed to constant UV radiation is $1.8-2$ $\mu \mathrm{m}$ and that the rest of the coating is identical to the unexposed coating (both chemically and mechanically). It therefore seems plausible to assume that either a lack of oxygen or of UV radiation in the bulk

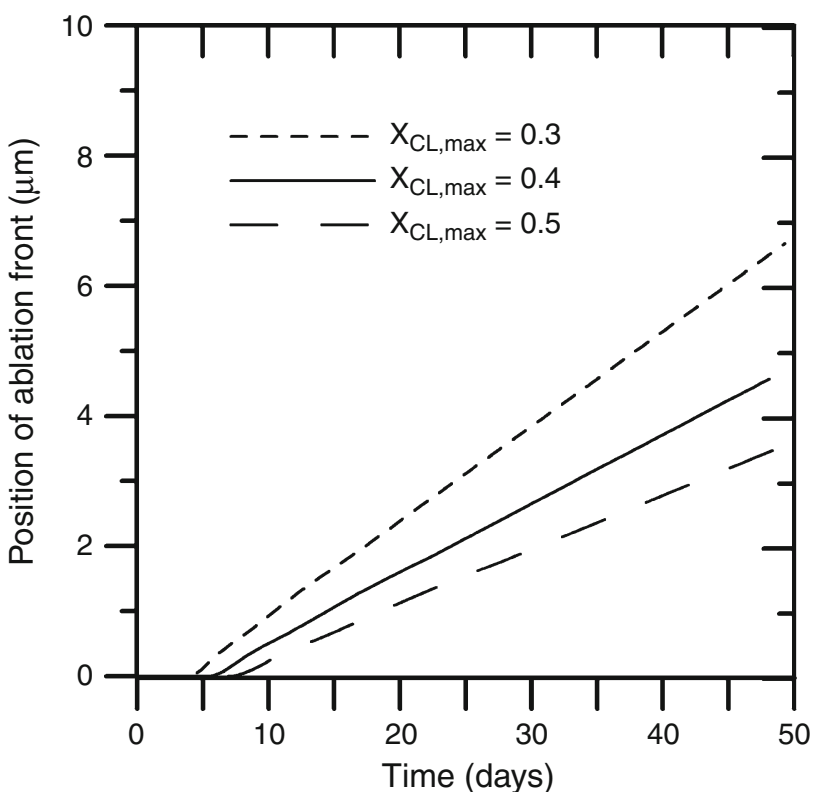

Fig. 13: Sensitivity plot with respect to $X_{\mathrm{CL}, \max }$ in a pigment-free epoxy-amine coating. Conditions and parameters (except the one in the legend) are the same as in the caption of Fig. 3 . $X_{\mathrm{CL}, \max }=0.4$ corresponds to the simulation in Fig. 3. The stable thickness of the oxidation zone varies from 1.91 to $1.96 \mu \mathrm{m}$ (highest thickness for largest value of $\left.X_{C L, \max }\right)$

of the coating has a strong influence on the oxidation zone thickness in these systems. However, it may not be possible to make a general statement on this matter because it depends on the relative rates of oxygen permeability in the coating, chemical reaction rates, and the UV radiation intensity. Rivaton et al. ${ }^{55}$ have measured photooxidation profiles in phenoxy resins and shown that the oxidation zone after 6 days reached a depth of about $100 \mu \mathrm{m}$ in a $190-\mu \mathrm{m}$-thick pigmentfree coating. The phenoxy resins applied were physically drying binders (molecular weight of $30,000-70,000 \mathrm{~g} / \mathrm{mol}$ ) that do not crosslink. Rivaton et al. state that the observed profile has to be mainly attributed to limited oxygen diffusion, but also partly to absorption by photoproducts. Similarly, Mailhot et al. ${ }^{52,53}$ have found a photooxidation profile that reaches $300 \mu \mathrm{m}$ into an epoxy-amine coating. In this case the cured resin had a glass transition temperature of only $-50^{\circ} \mathrm{C}$. The dominating mechanisms therefore depend very much on the epoxy coating system considered when the oxidation zone thickness can vary from about 2 to $300 \mu \mathrm{m}$. In the case of other nonepoxy binders or coatings the oxidation zone thickness can become much wider than $2 \mu \mathrm{m}$ (see e.g., Gerlock et al. ${ }^{64}$ ). For some multilayer systems delamination and color changes of base coats under unfortified clearcoats have been observed, which is evidence that both oxygen and UV radiation have penetrated the clearcoat. Discolored wood under clearcoats and occasional delaminations of clearcoats from basecoats on 
automobiles exposed to UV radiation also suggest that there can be plenty of oxygen deep in a coating system to facilitate photooxidation. Coming back to the epoxy-amine coatings of this work, the glass transition temperature and crosslink density are known to influence greatly the permeability of oxygen in a coating. ${ }^{1}$ The model of this work is able to handle both a UV radiation and oxygen permeability limited zone thickness. The Beer-Lambert law (equation 16) takes into account absorption of UV radiation and the fronttracking equation for the oxidation front (equation 14) handles the effect of oxygen. Which mechanism dominates is simply a matter of the parameter values provided to the model. If the oxygen permeability is increased then the zone thickness increases and if the absorption of UV radiation is increased then the UV radiation intensity inside the coating is reduced. The transient development in the absorption of UV radiation, until a stable value is obtained (after 10-20 days in the experiments used in this work), is not included in the model. A molar absorptivity of UV radiation, equal to that of carbonyl groups, and a constant concentration, equal to that of the original number of phenoxy groups, was used. Rivaton et al. ${ }^{55}$ have shown in their Fig. 2 that this assumption is not right for phenoxy resins, the UV (and visible) absorbance increases over the 25 days considered in good agreement with the well-known yellowing of many epoxy resins. To evaluate the importance of the model assumption for the densely crosslinked systems considered in this work, the Beer-Lambert law (equation 16) can be used. Assuming that a strong UV radiation absorption greatly influences the zone thickness, the concentration of the absorbing species in the oxidation zone required can be crudely calculated assuming a homogenous concentration of absorbent in the oxidation zone. The radiation intensity must be reduced to, say, $1 \%$ of the entering radiation so that $E_{l} / E_{\mathrm{o}}=0.01$. The molar UV absorptivity, $\alpha$, is taken to be that of carbonyl (see Table 1), which is the main absorbent formed (see Rezig et al. ${ }^{13}$ ), and $l$ is $2 \mu \mathrm{m}$ (the experimental value for the approximate zone thickness). Using the BeerLambert law, this gives an absorbent concentration of $10^{6} \mathrm{~mol} / \mathrm{m}^{3}$. For comparison, the maximum absorbent concentration that can possibly be formed if all $\mathrm{CHOH}$ and $\mathrm{CH}_{2} \mathrm{~N}$ groups of the original network are assumed to form absorbing groups with absorption capacities equal to that of carbonyl is close to $9000 \mathrm{~mol} / \mathrm{m}^{3}$ (using concentration data from the Fig. 1 caption of this work). Therefore, the concentration of carbonyl groups required to obtain a UV radiation limited zone thickness is at least a factor of 100 too high and the assumption that the low oxygen permeability is the main reason for the thin zone thickness seems valid (at least for the examples considered in this work). This mechanism is also in agreement with the conclusions of Monney and co-workers, ${ }^{65,66}$ who did the experimental zone thickness measurements.

Further evidence that oxygen permeability influences the rate of degradation is the simulations and experimental data of Figs. 8 and 9 in this work, where the only parameter varied from Figs. 8 and 9 is the relative humidity, which was reduced from $75 \%$ to $9 \%$. It was shown in a previous paragraph that both the constant value of the ablation lag time and the large drop in ablation rate observed experimentally, when the relative humidity is reduced, could be described by the model via a reduction of the oxygen diffusion coefficient only. This is in good agreement with many references (e.g., Schulz ${ }^{1}$ ) stating that the diffusion coefficient of oxygen is strongly dependent on relative humidity because moisture reduces the glass transition temperature of the binder network. If, on the other hand, the zone thickness should be limited by a strong absorption of UV radiation then an alternative mechanism for the change in the experimental data from Figs. 8 and 9 is required. It has not been possible to identify such a mechanism.

A consequence of this analysis is that there is little absorption of UV radiation in the $1-2 \mu \mathrm{m}$ wide oxidation zone and therefore a description of the transient development in the UV radiation absorption capacity is not required in the model (even though it takes place). This is also in agreement with the experience that commercial UV absorbers (unless used in prohibitively high concentrations) can only provide weak protection of the outermost micrometers of a clearcoat and such additives must be used in combination with free-radical scavengers (e.g., HALS) to provide adequate protection against UV radiation. ${ }^{1,35}$ Furthermore, clearcoats (containing organic UV absorbers in small amounts) are in general known to provide less UV radiation protection than pigmented systems of, e.g., wooden substrates, which also suggests that UV radiation is not completely absorbed by photoproducts in the top layers of coatings.

Schulz ${ }^{1}$ states that numerous studies have demonstrated that oxygen diffusion in transparent polymer films is the rate-determining step and refers to experiments in pure oxygen, as opposed to air, clearly showing an effect of oxygen concentration in the gas phase on the rate of degradation. Seubert et al., ${ }^{57}$ on the other hand, mention that the accepted belief has been that the availability of oxygen was never a rate limiting process in the photooxidation of binders, but then also show that for UV-curable urethane acrylate clearcoats the oxidation can indeed be oxygen diffusion-limited.

\section{Natural exposure vs artificial exposure}

A challenging issue, assuming oxygen permeability has a strong influence on the oxidation zone thickness, is that a larger zone thickness could be expected under natural weathering where the UV radiation intensity is lower and night cycles would allow much deeper diffusion of oxygen. The effect of lower radiation intensity can be investigated using the model simulations of Fig. 12. In this plot, $k_{1}$ is varied a factor of 4 
equivalent to a factor of 16 in the UV radiation intensity (see the square root dependency in equation 7). Simulations suggest that such an increase in radiation intensity only leads to an increase in the oxidation zone thickness from 1.63 to $2.3 \mu \mathrm{m}$, which is probably too small a change to be detected experimentally. The reason for this result is that simulations are not very sensitive to the UV radiation intensity as discussed in the section on sensitivity analysis, in good agreement with the data of Dubois et al. ${ }^{67}$ where the same ablation rates were found for a light energy of 60 and $75 \mathrm{~W} / \mathrm{m}^{2}$. This experimental observation was hypothesized by the authors as being due to a lightenergy threshold above which the oxygen diffusion gradient in the thin layer limits the ablation rate. However, for many commercial coatings (e.g., for automobiles) the addition of UV absorbers has been found to confine degradation to the top of the coatings. Therefore, in the more common case of wide oxidation zones in nonprotected coatings, UV absorbers can have a strong beneficial effect on the oxidation zone thickness, which will not be observed for the model coatings of this work where the oxidation zone thickness is very low $(<2 \mu \mathrm{m})$ even in the absence of UV absorbers.

The effect of night cycles is interesting. During the night there is no oxygen consumption and the next morning the coating will contain more oxygen. This is expected to increase the rate of degradation. No data have been found that can clarify this point directly, but in Fig. 4 in Dubois et al., ${ }^{67}$ the linear decrease in coating thickness of a densely crosslinked epoxy system as a function of cumulative radiation intensity (as opposed to time) is shown for two conditions of natural weathering and one condition of artificial UV radiation exposure (conditions of constant UV radiation intensity). The ablation rates are 4-6 times higher for natural compared with artificial exposure. Dubois et al. ascribe this to the influence of rain and it is not possible to confirm whether the increased oxygen concentration during night cycles also adds to the increased ablation rate. The thickness of the oxidation zone was not reported. Initially, in the artificial exposures considered in this work, there is a short period where neither oxygen nor UV radiation should be limited (coating contains oxygen and no photoproducts are present). Under these conditions, the presence of photoproducts deeper in the coating may be expected, but such an observation has not been reported by Monney and co-workers in their many analyses of the oxidation zone thickness. ${ }^{37,38,63,65-67}$ The reason for this could be that the concentration of photoproducts does not reach a sufficiently high value for detection in the time available.

Summarizing, no data have been found that are in strong disagreement with the assumptions of this work, but it must also be emphasized that the assumptions are only valid for the densely crosslinked model epoxy systems used for model validation and under constant artificial UV radiation exposure conditions in the absence of any water spray or dark cycles. Most commercial coating systems, due to the binder types and additives used, are expected to react much more slowly with UV radiation and oxygen. In addition, the oxygen permeability may be higher and it seems likely that such coatings may have greater oxygen content in their depth.

\section{Validation of model assumptions}

The model is based on a number of simplifying assumptions that have not all been verified in the above discussion. Here, the most important ones are readdressed.

Diffusivities in the coating of all active groups were assumed to be negligible. This seems to be a reasonable assumption as discussed by Colin. ${ }^{27}$

Water absorption in the coating was assumed to be independent of coating degradation. This is reasonable because the oxidation zone is very thin compared with the initial thickness of the coating. However, Oosterbroek et al. ${ }^{68}$ claim that it was not a good assumption for a weathered polyurethane clearcoat, where water absorption increased five times during weathering.

Reflection of UV radiation at the coating-substrate interface was neglected. Depending on the type of substrate used, this may not be a good assumption. However, the exact nature of the substrates used by the various investigators is rarely reported.

Skeleton breaking reactions, due to internal stress, was neglected. According to Bellenger and Verdu ${ }^{29}$ such a scission reaction should lead to formation of aldehyde groups, which have not been observed by Rezig et al. ${ }^{13}$ Relaxation phenomena were also neglected because the coatings were all allowed to cure at ambient conditions (see Croll et al. ${ }^{43}$ for more on this issue).

The porosity of the coating, at a given position in the oxidation zone, is assumed to be a function of the fraction of crosslinks that have been broken by reaction (1). This is a very crude assumption that needs further investigation. However, the benzene ring structure disappears from at least the outer part of the oxidation zone ${ }^{12}$ so some porosity must be formed. It may be that a critical number of the initial crosslinks must be broken before porosity can appear, but there is presently no data available to confirm this.

Internal stress in the coating was considered indirectly only via the value used for the adjustable parameter $X_{\mathrm{CL}, \max }$, which takes into account mechanical properties. Under cyclic exposure conditions, $X_{\mathrm{CL}, \max }$ may depend on the exposure history, but for the constant conditions considered in this work, the approximation seems adequate.

Moisture (water) does not react with the cured epoxy structure. This assumption was not confirmed.

It was also assumed that all active groups in the network react independently of one another. This assumption has not been verified. 
Summarizing, most assumptions are justified, but some assumptions need confirmation. Presently, the uncertainties will be lumped into the values used for the adjustable constants.

\section{Conclusions}

A mathematical model describing coating degradation under constant artificial exposure conditions was developed. The relevant phenomena, photoinitiated oxidation reactions, intrafilm oxygen permeability, water absorption and diffusion, reduction of crosslink density, and development of a thin surface oxidation zone, were all included. Experimental data available for three independent epoxy-amine case studies can be quantitatively simulated by the model. An important prediction of the model is that the thickness of the surface oxidation zone, depending on the exposure conditions and binder systems employed, is between 0.5 and $2 \mu \mathrm{m}$, in good agreement with experimental observations. Furthermore, it was confirmed that degradation rates, in the absence of UV absorbers and antioxidants, are quite dependent on oxygen solubility and the diffusion coefficient of oxygen in the oxidation zone. The latter parameter is a strong function of relative humidity. The addition of less than $1 \mathrm{wt} \%$ multiwalled carbon nanotubes was found to significantly improve the cohesiveness of the surface oxidation zone and thereby reduce the rate of coating degradation by more than $30 \%$. There has been no attempt to model gloss loss, speciation of volatile end products, loss of adhesion, cracking, color change, or blistering. In addition it should be mentioned that the present model has only been validated for the model epoxy systems considered and under constant artificial UV radiation exposure conditions in the absence of any water spray or dark cycles. For other binder types (or lower crosslink densities) or when dark periods are included, the oxidation zone thickness may be substantially larger than the $1-2 \mu \mathrm{m}$ seen in this work, which may potentially render UV radiation absorption in the outer degraded layers of the coating of more importance.

An important next step, encouraged by Floyd, ${ }^{25}$ will be to consider dynamic conditions and thereby provide simulations of coating behavior in various cyclic exposure scenarios being used in accelerated testing equipment (Nichols et al ${ }^{69}$ have recently suggested a new testing protocol). Subsequently, conditions of natural weathering should be considered. In addition, it may be investigated how the effects of, e.g., UV radiation absorbers and light stabilizers can be included in the model.

The model approach can be extended to other coating systems provided experimental data and observations are available for calibration of the model. If any essential special rate phenomena occur, e.g., a hydrolysis reaction ${ }^{17,48,50}$ or reactions of photoactive pigments, ${ }^{70}$ detailed experimental data are required prior to incorporation of these rate-influencing steps in the model.

In principle, the model can be used for predicting in-service coating behavior, based on well-controlled and extensive accelerated laboratory measurements, by calibration of the model parameters. This way, the statistical influence of variation in raw materials and other uncertainties are lumped into the model parameters. In this respect, the model is similar to the statistical models. However, the reliability of this extrapolation approach has not yet been studied. The model is best calibrated if all relevant data are provided with the exposure data (see the caption of Fig. 3 for the data required). Furthermore, simultaneous measurements of rates of mass loss, ablation, and formation of photoproducts, as well as oxidation zone thickness measurements, on the same well-characterized coatings would be very useful.

An important issue that needs further investigation is a more detailed characterization of the surface oxidation zone. The approximate thickness of this zone and the surface morphology in the top $10-30 \mathrm{~nm}^{13,56}$ have been studied for epoxy-amine coatings, but the porosity, glass transition, and crosslink density profiles, phase behavior, and oxygen solubility and diffusion rates are needed to verify some of the assumptions made in this work. It would also be interesting to find out how the oxidation zone of densely crosslinked epoxy-amine networks differ from that of other networks and full commercial coating systems.

Acknowledgments The author is grateful to the manuscript reviewers for their helpful comments. Financial support by J. C. Hempel's Foundation is gratefully acknowledged.

Open Access This article is distributed under the terms of the Creative Commons Attribution Noncommercial License which permits any noncommercial use, distribution, and reproduction in any medium, provided the original author(s) and source are credited.

\section{References}

1. Schulz, U, Accelerated Testing. Vincentz, Hannover (2009)

2. Martin, J, Chin, JW, Nguyen, T, "Reciprocity Law Experiments in Polymeric Photodegradation: A Critical Review." Prog. Org. Coat., 47 292-311 (2003)

3. Sørensen, PA, Kiil, S, Weinell, CE, Dam-Johansen, K, "Anticorrosive Coatings-A Review." J. Coat. Technol. Res., 6 (2) 135-177 (2009)

4. Wypych, G, Handbook of Material Weathering, 4th ed. Chem Tech Publishing, Toronto (2008)

5. Gerlock, JL, Bauer, DR, Briggs, LM, "Photostability of Acrylic/Melamine Enamels. Effect of Polymer Composition and Polymerization Conditions on Photo-initiation Rates." Prog. Org. Coat., 15 197-208 (1987)

6. Dickie, RA, "Chemical Origins of Paint Performance." J. Coat. Technol., 66 (834) 29-37 (1994) 
7. Martin, JW, Nguyen, T, Byrd, E, Dickens, B, Ned, E, "Relating Laboratory and Outdoor Exposures of Acrylic Melamine Coatings I. Cumulative Damage Model and Laboratory Exposure Apparatus." Polym. Degrad. Stab., 75 193-210 (2002)

8. Martin, JW, Chin, JW, Byrd, WE, Embree, E, Kraft, KM, "An Integrating Sphere-Based Ultraviolet Exposure Chamber Design for the Photodegradation of Polymeric Materials." Polym. Degrad. Stab., 63 297-304 (1999)

9. Bierwagen, GP, "The Science of Durability of Organic Coatings: A Foreword." Prog. Org. Coat., 15 179-185 (1987)

10. Verdu, J, Colin, X, Fayolle, B, Audouin, L, "Methodology of Lifetime Prediction in Polymer Aging." J. Test. Eval., 35 (3) 289-296 (2011)

11. Croll, S, Hinderliter, B, "Estimating Service Life Times in Weathering: An Optimistic View." J. Coat. Technol. Res., 4 (3) 217-230 (2007)

12. Nguyen, T, Pellegrin, B, Bernard, $\mathrm{X}, \mathrm{Gu}, \mathrm{J}$, Gorham, $\mathrm{P}$, Stutzman, P, Shapiro, A, Byrd, E, Chin, J, "Degradation and Nanoparticle Release of Nanocomposite Coatings Exposed to UV Radiation." Coatings Science International, Nordwijk, The Netherlands, Book of abstracts, pp. 16-21, 2010

13. Rezig, A, Nguyen, T, Martin, D, Sung, L, Gu, X, Jasmin, J, Martin, J, "Relationship Between Chemical Degradation and Thickness Loss of an Amine-Cured Epoxy Coating Exposed to Different UV Environments." J. Coat. Technol. Res., 3 (3) 173-184 (2006)

14. Guillot, L, Monney, L, Dubois, C, Chambaudet, A, “Testing of Organic Matrix Durability in Photochemical Ageing Using Ablation Measurements." Polym. Degrad. Stab., 72 209-215 (2001)

15. Monney, L, Dubois, C, Chambaudet, A, "Ablation of Organic Matrix: Fundamental Response of a Photo-Aged Epoxy-Glass Fibre Composite." Polym. Degrad. Stab., 56 357-366 (1997)

16. Kiil, S, "Quantification of Simultaneous Solvent Evaporation and Chemical Curing of Thermoset Coatings." J. Coat. Technol. Res., 7 (5) 569-586 (2010)

17. Bauer, DR, "Predicting In-Service Weatherability of Automotive Coatings: A New Approach." J. Coat. Technol., 69 (864) 85-96 (1997)

18. Martin, JW, "A Stochastic Model for Predicting the Service Life of Photolytically Degraded Poly(methyl methacrylate) Films." J. Appl. Polym. Sci., 29 777-794 (1984)

19. Martin, JW, "Quantitative Characterization of Spectral Ultraviolet Radiation-Induced Photodegradation in Coating Exposed in the Laboratory and the Field." Prog. Org. Coat., 23 49-70 (1993)

20. Martin, JW, Saunders, SC, Wineburg, JP, Methodologies for Predicting the Service Life of Coatings Systems. Federation of Societies for Coatings Technology, Blue Bell, PA (1996)

21. Guseva, O, Brunner, S, Richner, P, "Service Life Prediction for Aircraft Coatings." Polym. Degrad. Stab., 82 1-13 (2003)

22. Dickens, B, "Model-Free Estimation of Outdoor Performance of a Model Epoxy Coating System Using Accelerated Test Laboratory Data." J. Coat. Technol. Res., 6 (4) 419-428 (2009)

23. Hinderliter, B, Croll, S, "Monte Carlo Approach to Estimating the Photodegradation of Polymer Coatings." J. Coat. Technol. Res., 2 (6) 483-491 (2005)

24. Wood, KA, Robien, SA, "A Quantitative Model for Weathering-Induced Mass Loss in Thermoplastic Paints, Chapter 30." In: Martin, JW, Ryntz, RA, Chin, J, Dickie, RA (eds.) Service Life Prediction of Polymeric Materials-Global Perspectives. Springer, New York (2009)
25. Floyd, FL, "Implementing What We Have Learned, Chapter 33." In: Martin, JW, Ryntz, RA, Chin, J, Dickie, RA (eds.) Service Life Prediction of Polymeric Materials-Global Perspectives. Springer, New York (2009)

26. Monney, L, Dubois, C, Chambaudet, A, "Trapping and Identification of Volatile Photo-Products of a Photo-Oxidised Epoxy Matrix." Polym. Degrad. Stab., 66 17-22 (1999)

27. Colin, X, Marais, C, Verdu, J, "A New Method for Predicting the Thermal Oxidation of Thermoset Matrices-Application to an Amine Crosslinked Epoxy." Polym. Test., 20 795-803 (2001)

28. Bellenger, V, Verdu, J, Francillette, J, Hoarua, P, "PhotoOxidation of Epoxy Model Compounds." Polym. Commun., 27 279-281 (1986)

29. Bellenger, V, Verdu, J, "Oxidative Skeleton Breaking in Epoxy-Amine Networks.” J. Appl. Polym. Sci., 30 363-374 (1985)

30. Bellenger, V, Bouchard, C, Claverirolle, P, Verdu, J, "PhotoOxidation of Epoxy Resins Cured by Non-Aromatic Amines." Polym. Photochem., 1 69-80 (1981)

31. Bellenger, V, Verdu, J, "Photo-Oxidation Amine Crosslinked Epoxies I. The DGEBA-DDM System." J. Appl. Polym. Sci., 28 2599-2609 (1983)

32. Bellenger, V, Verdu, J, "Photo-Oxidation Amine Crosslinked Epoxies II. Influence of Structure." J. Appl. Polym. Sci., 28 2677-2688 (1983)

33. Bellenger, V, Verdu, J, "Structure-Photooxidative Relationship of Amine-Crosslinked Epoxies." Polym. Photochem., 5 295-311 (1984)

34. Ollier-Dureault, V, Bosse, B, "Photooxidation of Anhydride-Cured Epoxies: FTIR Study of the Modifications of the Chemical Structure." J. Appl. Polym. Sci., 70 1221-1237 (1998)

35. Wicks, ZW, Jones, FN, Pappas, SP, Wicks, DA, Organic Coatings-Science and Technology, 3rd ed. Wiley, New York (2007)

36. Christensen, PA, Dilks, A, Egerton, TA, Temperley, J, "Infrared Spectroscopic Evaluation of the Photodegradation of Paint." J. Mater. Sci., 35 5353-5358 (2000)

37. Monney, L, Rouge, N, Dubois, C, Chambaudet, A, "Photochemical Degradation Study of an Epoxy Material by X-ray Analysis." Polym. Degrad. Stab., 62 367-371 (1998)

38. Monney, L, Rouge, N, Dubois, C, Chambaudet, A, "Photochemical Degradation Study of an Epoxy Material by IRATR Spectroscopy." Polym. Degrad. Stab., 62 353-359 (1998)

39. Hill, L, "Calculation of Crosslink Density in Short Chain Networks." Prog. Org. Coat., 31 (3) 235-243 (1997)

40. Kiil, S, Bhatia, SK, Dam-Johansen, SK, "Solution of Transient Problems with Steep Gradients: Novel Front-Tracking Strategy." Chem. Eng. Sci., 50 (17) 2793-2799 (1995)

41. Levenspiel, O, Chemical Reaction Engineering, 3rd ed. Wiley, New York (1999)

42. Kiil, S, "Drying of Latex Films and Coatings: Reconsidering the Fundamental Mechanisms." Prog. Org. Coat., 57 236-250 (2006)

43. Croll, SG, Shi, X, Fernando, BMD, "The Interplay of Physical Aging and Degradation During Weathering for Two Crosslinked Coatings." Prog. Org. Coat., 61 136-144 (2008)

44. Ramachandran, PA, Dudukovic, MP, "A Moving FiniteElement Collocation Method for Transient Problems with Steep Gradients." Chem. Eng. Sci., 39 (7-8) 1321-1324 (1984)

45. Maggana, C, Pissis, P, "Water Sorption and Diffusion Studies in an Epoxy Resin System." J. Polym. Sci., 37 1165-1182 (1999) 
46. Dé Nève, B, Shanahan, MER, "Water Absorption by an Epoxy Resin and Its Effect on the Mechanical Properties and Infra-Red Spectra." Polymer, 34 (24) 5099-5105 (1993)

47. Zou, C, Dubois, C, Chambaudet, A, "The Effect of Water Absorption on the Dielectric Properties of Epoxy Nanocomposites." IEEE Trans. Dielectr. Insulation, 15 (1) 107117 (2008)

48. Nguyen, T, Martin, JW, Byrd, E, Embree, N, "Effects of Relative Humidity on Photodegradation of Acrylic-Melamine Coatings: A Quantitative Study." Vol. 83, Proceedings of PSME, ACS, Washington DC, pp. 118-119 (2000)

49. Bateman, L, "Olefin Oxidation." Quart. Rev., 8 (2) 147-167 (1954)

50. Bauer, DR, "Global Exposure Models for Automotive Coating Photo-Oxidation." Polym. Degrad. Stab., $69297-$ 306 (2000)

51. Chin, JW, Martin, J, Embree, E, Byrd, E "The Use of Integrating Spheres as Uniform Sources for Accelerated UV Weathering of Advanced Materials." Vol. 83, Proceedings of $A S M E$, PSME fall meeting, ACS, August 20-24, Washington DC, pp. 145-146 (2000)

52. Mailhot, B, Morlat-Therias, S, Ouahioune, M, Gardette, J, "Study of the Degradation of an Epoxy/Amine Resin 2: Kinetics and Depth-Profiles." Macromol. Chem. Phys., 206 585-591 (2005)

53. Mailhot, B, Morlat-Therias, S, Ouahioune, M, Gardette, J, "Study of the Degradation of an Epoxy/Amine Resin 1: Photo- and Thermo-Chemical Mechanisms." Macromol. Chem. Phys., 206 575-584 (2005)

54. Kiil, S, Weinell, CE, Pedersen, MS, Dam-Johansen, K, "Analysis of Selfpolishing Antifouling Paints Using Rotary Experiments and Mathematical Modelling." Ind. Eng. Chem. Res., 40 (18) 3906-3920 (2001)

55. Rivaton, A, Moreau, L, Gardette, J, "Photo-Oxidation of Phenoxy Resins at Long and Short Wavelengths-I. Identification of the Photoproducts." Polym. Degrad. Stab., 58 321-332 (1997)

56. Gu, XH, Nguyen, T, Oudina, M, Martin, D, Kidah, B, Jasmin, J, Rezig, A, Sung, LP, Byrd, E, Martin, JW, "Microstructure and Morphology of Amine-Cured Epoxy Coatings Before and After Outdoor Exposures-An AFM Study." J. Coat. Technol. Res., 2 (7) 547-556 (2005)

57. Seubert, CM, Nichols, ME, Kucherov, AV, "Long-Term Weathering Behaviour of UV-curable Clearcoats: Depth Profiling of Photooxidation. UVA, and HALS Distributions." J. Coat. Technol. Res., 2 (7) 529-538 (2005)

58. Wessels, W, "Nanoscale Zinc Oxide for UV Stabilization in Paints and Coatings." 18th SLF Congress, 8-10 October 2006, Congress book, Helsingør, Denmark, pp. 93-100.
59. Aglan, A, Allie, A, Ludwick, A, Koons, L, "Formulation and Evaluation of Nano-Structured Polymeric Coatings for Corrosion Protection." Surf. Sci. Technol., 202 370-378 (2007)

60. Shi, X, Croll, SG, "Reduced Indentation Recovery Temperature at the Surface of a Crosslinked Epoxy Coating in Humid Conditions." J. Coat. Technol. Res., 8 (4) 535-539 (2011)

61. Perera, DY, Eynde, DV, "Moisture and Temperature Induced Stresses (Hygrothermal Stresses) in Organic Coatings." J. Coat. Technol., 59 (748) 55-63 (1987)

62. Misovski, T, Nichols, ME, Hardcastle, HK, "The Influence of Water on the Weathering of Automotive Paint Systems, Chapter 20.' In: Martin, JW, Ryntz, RA, Chin, J, Dickie, RA (eds.) Service Life Prediction of Polymeric Materials-Global Perspectives. Springer, New York (2009)

63. Delobelle, P, Guillot, L, Dubois, C, Monney, L, "PhotoOxidation Effects and Mechanical Properties of Epoxy Matrices: Young's Modulus and Hardness Analyses by Nano-Indentation.” Polym. Degrad. Stab., 77 465-475 (2002)

64. Gerlock, JL, Prater, TJ, Kaberline, SL, de Vries, JE, "Assessment of Photooxidation in Multi-Layer Coating Systems by Time-of-Flight Secondary Ion Mass Spectroscopy." Polym. Degrad. Stab., 47 405-441 (1995)

65. Monney, L, Dubois, C, Chambaudet, A, "Evolution of the Thin Photo-Oxidation Layer of an Epoxy Matrix During Artificial Photo-Ageing." Die Angew. Makromol. Chem., 273 6-11 (1999)

66. Monney, L, Dubois, C, Villa, F, Chambaudet, A, "Surface Removal of a Weathered Organic Glass." J. Non-Cryst. Solids, 260 208-215 (1999)

67. Dubois, C, Monney, L, Bonnet, N, Chambaudet, A, "Degradation of an Epoxy-Glass-Fibre Under Photo-Oxidation/ Leaching Complementary Constraints." Compos. Part A, $\mathbf{3 0}$ 361-368 (1999)

68. Oosterbroek, M, Lammers, RJ, van der Ven, LGJ, Perera, DY, "Crack Formation and Stress Development in an Organic Coating." J. Coat. Technol., 63 (797) 55-60 (1991)

69. Nichols, ME, Boisseau, J, Pattison, L, Quill, J, Misovski, T, Peters, CA, Zhang, J, Henderson, K, Smith, D, Seebergh, JE, Berry, DH, "Accelerated Weathering Testing: A New Approach to Anticipating Florida Exposure Results." Coatings Science International, Nordwijk, The Netherlands, Book of abstracts, p. 76 (2011)

70. Zhang, WR, Hinder, SJ, Smith, R, Lowe, C, Watts, JF, “An Investigation of the Effect of Pigment on the Degradation of a Naturally Weathered Polyester Coating.' J. Coat. Technol. Res., 8 (3) 329-342 (2011) 